University of San Diego

Digital USD

Spring 5-22-2021

\title{
Utilizing Post Graduate Residency Program in New Graduate Nurse Practitioners to Improve Clinical Outcomes
}

LaShaunda Jethro

University of San Diego, lashaunda.jethro@yahoo.com

Follow this and additional works at: https://digital.sandiego.edu/dnp

Part of the Nursing Commons

\section{Digital USD Citation}

Jethro, LaShaunda, "Utilizing Post Graduate Residency Program in New Graduate Nurse Practitioners to Improve Clinical Outcomes" (2021). Doctor of Nursing Practice Final Manuscripts. 165.

https://digital.sandiego.edu/dnp/165

This Doctor of Nursing Practice Final Manuscript is brought to you for free and open access by the Theses and Dissertations at Digital USD. It has been accepted for inclusion in Doctor of Nursing Practice Final Manuscripts by an authorized administrator of Digital USD. For more information, please contact digital@sandiego.edu. 
UNIVERSITY OF SAN DIEGO

Hahn School of Nursing and Health Science: Beyster Institute for Nursing Research

DOCTOR OF NURSING PRACTICE PORTFOLIO

by

LaShaunda R Jethro

A portfolio presented to the

FACULTY OF THE HAHN SCHOOL OF NURSING AND HEALTH SCIENCE:

BEYSTER INSTITUTE FOR NURSING RESEARCH

UNIVERSITY OF SAN DIEGO

In partial fulfillment of the

requirements for the degree

DOCTOR OF NURSING PRACTICE

May/2021 
Utilizing Post Graduate Residency Program in New Graduate Nurse Practitioners to Improve Clinical Outcomes.

Copyright (C) 2021

by LaShaunda R Jethro 


\section{ACKNOWLEDGEMENTS}

I want to start by giving thanks to my heavenly father, who is the head of my life and giver of my salvation. Thank you for making what I thought was impossible, possible. Father, you have been that one set of footsteps in the sand carrying me through this journey. During my lowest points and darkest days, you kept my mind on you and reaching for the blessings you have in store. Through you, I know my future is secure

To my three children Kiara, Cierra, and Trey, I love you more than I could ever express through words. My greatest joy is being your mother. Your love and support have been a blessing. You lifted me when I was down, brought me food when I was hungry, and listened when I wanted to vent. There is no greater gift God could have given me than each of you. I love you with every heartbeat.

To my granddaughter Harper, just when I thought I could not love another human being more, you came along and opened a part of my heart I never knew existed. The love I have for you cannot be measured. You are indeed a blessing from God. Holding you in my arms is always enough to turn my cloudy days sunny. No title is more important to me than Lola. I love you with everything in me.

To my husband Howard, I could write a book about the many things you have done for our family. You have been my anchor, sounding board, best friend, cheerleader, and a great husband. Thank you for encouraging me and believing in me even when I didn't believe in myself. At times, you were a mother and a father while I studied or went to a meeting without ever complaining. I thank God for you every day. I look forward to spending the rest of my days with you. I Love You.

To my mother, I thank you for your unconditional love and support. Mother, you have been my role model for as long as I can remember. You set the bar by proving that you can 
be anything you want to be with hard work and dedication. There is no doubt the woman I am today is because of you. I shall cherish you for the rest of my days.

To my father Dementral, you have loved me as your own and welcomed me with open arms. Thank you for being my protector, my guide, and for loving me completely. I know I can always count on you to be there when I need you, and for that, I am genuinely grateful. I love you.

To my parents Howard Sr and Georgia Jethro, I am honored to have married your son. Your love for one another has taught me how to love your son for the past 23 years. You have treated me like a daughter since the beginning, and for that, I am eternally grateful. Thank you for your love, belief, and encouragement. I love you.

To my grandfather, my sisters, brothers, aunts, uncles, nephews, nieces, cousins, great-nephew, God Mother Corrine, and best friend Catina, I am so thankful for the bonds we share. Thank you for the love and support you've given me. I appreciate each one of you. I pray that God continues to bless and watch over you.

To my faculty chair Dr. Joseph Burke, thank you for your leadership and faith you had in me completing this journey. You remained steadfast and undeterred through every bump and pitfall. You pushed me to challenge myself and reach for the finish line. I shall never forget all you have done for me. From the bottom of my heart, thank you.

To my mentor Dr. Khadija Hamisi, we were destined to meet. God placed you as a coach, teacher, and leader in my life. You answered every call, text, and email. You pushed me in clinical to be better than average. You have been a true example of excellence and selflessness. 


\begin{abstract}
Utilizing Post Graduate Residency Program in New Graduate Nurse Practitioners to Improve Clinical Outcomes.

by LaShaunda R Jethro

The Advanced Practiced Registered Nurse (APRN) role across the continuum of patient care continues to evolve, and the APRN continues to play a significant part in sustaining the current healthcare system and controlling the rising incidence of mortality and medical cost. While a substantial amount of evidence demonstrates that Nurse Practitioners (NPs) are expert healthcare providers, some studies also report that many new NPs fail to be confident in their capability to undertake the NP role and attend to increasing patient loads. Some school of thought posits that post-graduate residency programs support new nurse practitioners to transition successfully to new specialties and provides them with chances to learn effective management skills and affirm their confidence as they take on their new roles. The DNP Essential VIII emphasizes the vital role of the APRN as a leader with creative clinical knowledge to solve various clinical problems using evidence-based research to improve health outcomes. Fulfilling the above role is the reason for this clinical inquiry. Therefore, this white paper focuses on establishing whether post-graduate residency programs increase Nurse Practitioners' clinical outcomes.
\end{abstract}

Keywords: post-graduate residency programs for NPs; effects of post-graduate residency programs on NPs; clinical outcomes of post-graduate residency programs. 


\section{TABLE OF CONTENTS}

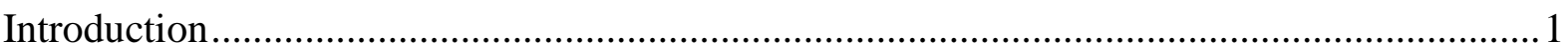

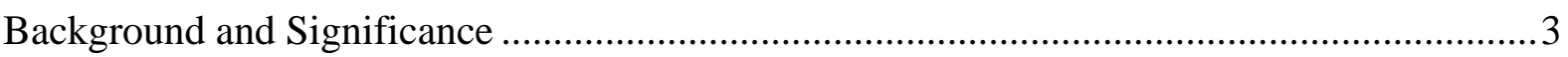

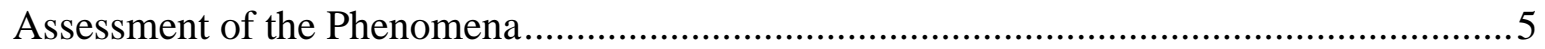

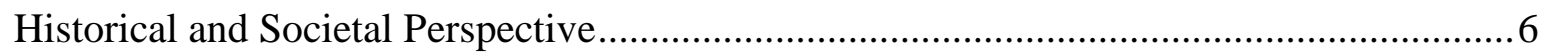

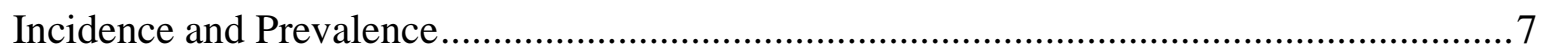

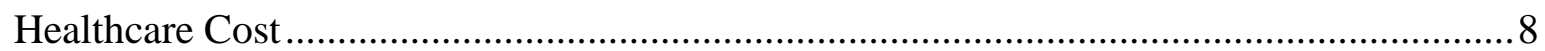

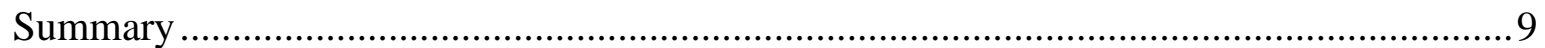

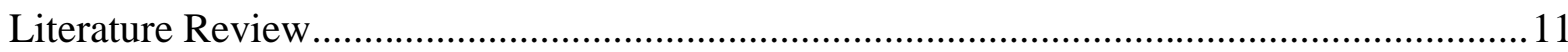

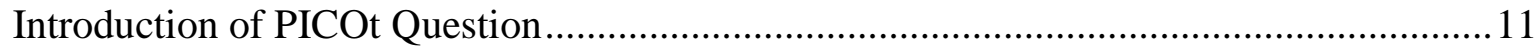

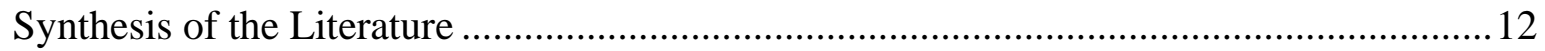

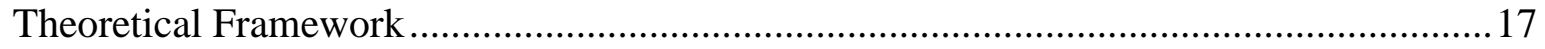

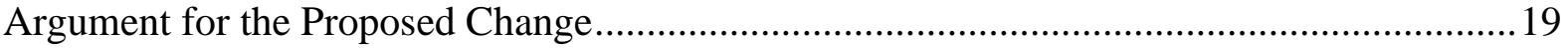

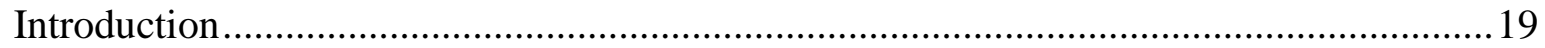

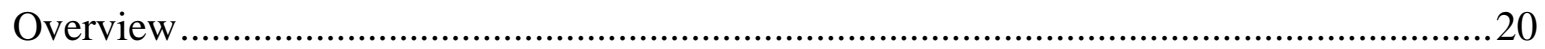

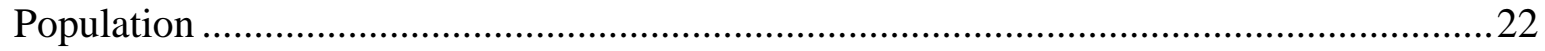

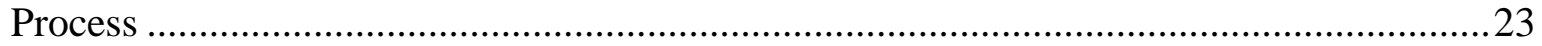

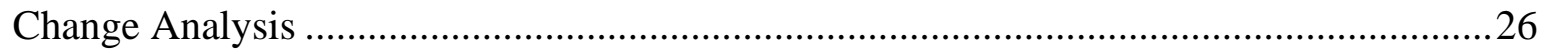

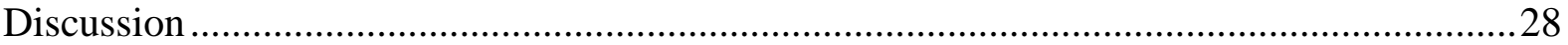

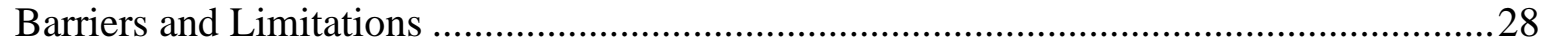

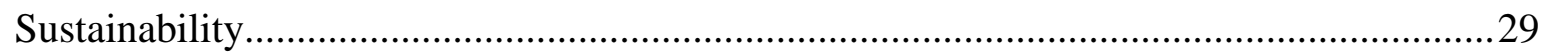

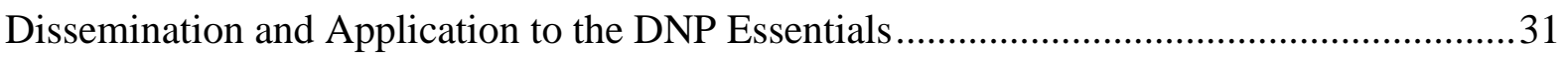




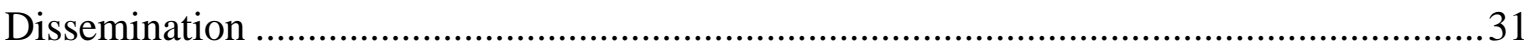

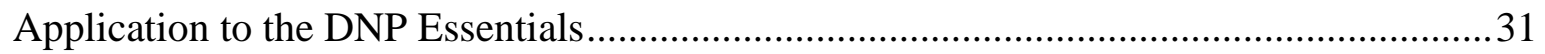

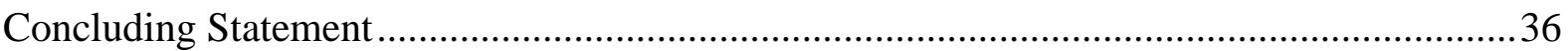

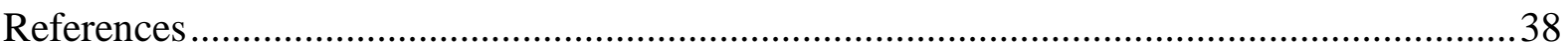




\section{Introduction}

A doctorate in nursing practice (DNP) places Nurse Practitioners (NPs) and other advanced practice registered nurses (APRNs) possessing high levels of clinical competencies at the epitome of clinical nursing practice and leadership. The high level of DNP-prepared nurses' expertise in clinical practice strategically positions them in meeting the Institute of Medicine's (IOM) mandate of improving healthcare (Edwards, Coddington, Erler \& Kirkpatrick, 2018). These clinical competencies are like other disciplines requiring doctoral education, such as medicine, physical therapy, psychology, and pharmacy. Across the globe, it is notable that these other disciplines offer clinical residency programs that align with the objectives of the curriculum designed for each discipline. However, nursing practice is the only discipline that lacks funding and requirements for a systematic clinical residency program or training for advanced practice roles (Mounayar \& Cox, 2020). Different schools of thoughts have proffered the futility or usefulness of having a post-graduate residency program for Nurse Practitioners, arguing that post-graduate clinical training does or does not improve clinical outcomes (Nelson, 2017; Meissen, 2019; McCauley et al., 2020; Harper, McGuiness \& Johnson, 2017). This white paper investigated these different schools of thought. However, this white paper intends to posit that post-graduate residency programs increase Nurse Practitioners' clinical outcomes with supporting pieces of literature. The white paper investigated the clinical training and looked critically at policy issues that clarify the role post-graduate clinical residencies play during the shift to DNP practice, specifically focusing on newly graduated NPs.

This white paper focused on distinctive clinical specialization. It looked at the background of Nurse Practitioner (NP) residency approaches within NP curriculums that align with the DNP Essentials with a particular emphasis on Essential VIII (American Association of Colleges of Nursing [AACN], 2006). Furthermore, this paper reviewed and 
described the historical and practice consequences of implementing NP residency programs and current residencies that support the transition to expert practice. Undeniably, as NP residencies acceptance increases in the healthcare field, more research is required on the outcomes of such programs on NPs job satisfaction, clinical competencies, and patient satisfaction. For instance, the first year of practice for NPs is a critical transitional period involving intricate professional growth as the new NPs must navigate through several facilitators and barriers of healthcare practice (Faraz 2019; Faraz, 2017). Therefore, it is imperative to clarify the need, direction, and program standards of post-graduate nursing residencies. 


\section{Background and Significance}

The emergence of the Patient Protection and Affordable Care Act (ACA) has created a greater need for access to care due to narrowing the effects of socioeconomic disparities on healthcare in the US society (Courtemanche, 2018; Griffith, Evans \& Bor, 2017). The greater need for care has consequently created a shortage for primary and acute care providers who must also overcome the challenges of delivering timely, high-quality, and cost-effective patient care in various healthcare facilities. For instance, literature by Poghosyan, Liu \& Norful (2017) report that in the US healthcare system, effective completion of preventive, acute, and chronic care guidelines recommended by national regulatory bodies necessitates available nurse practitioner professionals to spend lengthy clinical hours daily to cater for diverse patient volumes which have escalated after the enforcement of the ACA. Therefore, there is a backdrop in expanding the roles and scope of practice of available NPs in meeting the growing healthcare demand. This gap gets accentuated by the ongoing process of aging in society, increased number of insured individuals, shortages in primary care physicians, and the American population's growth (Norful et al., 2019). Researchers estimated that by 2020, over 157 million Americans would have a chronic disease, thereby necessitating high-quality healthcare despite a shortage of about 40,000 physicians (Norful et al., 2019). Such gaps created in patient care and the need to address the gap puts APRNs in a strategic position to fill the gaps.

Studies have shown that Advanced Practice Registered Nurses (APRNs) provide excellent and high-quality primary care comparable to physicians in managing common and chronic medical problems (Carranza, Munoz \& Nash, 2021). APRNs play an essential role in sustaining the current healthcare system and controlling the rising incidences of acute and chronic medical problems. For instance, patient outcomes such as satisfaction, mortality, physical and emotional wellbeing among patients attended by physicians equal that of 
patients treated by APRNs. Carranza Munoz \& Nash (2021) corroborate that nurse practitioners' high efficiency in various specialties results in clinical safety and positive patient outcomes achievement. Abraham, Norful, Stone \& Poghosyan (2019) heralds APRNs for cost-effective care for chronic illnesses compared to physician-led care. In other instances, the level of education passed on by physicians to patients is scanty, leaving some patients dissatisfied (Carranza Munoz \& Nash, 2021). In such scenarios, APRNs supersede expectations by promoting advocacy and adequate patient education compared to physicianled care.

While APRNs are effective, the need for more DNP-prepared nursing professionals gets adequately articulated by national nursing professional bodies. According to these bodies, DNP programs prepare nurse practitioners for clinical practice and leadership, restructuring healthcare, and translating research into clinical practice. For instance, the literature by Edwards, Coddington, Erler \& Kirkpatrick (2018) reports that the American Association of Nurse Anesthetists (AANA) set qualifying from a DNP program as the entrylevel requirement for practice by 2025. Similarly, the National Organization for Clinical Nurse specialists supported the AANA position by supporting a DNP requirement as the entry-level practice for specialized care. The AACN reiterates the need to prepare nurse practitioners for intricate clinical practice roles and assist nursing professionals in participating in multi-disciplinary healthcare teams. Such strong statements from professional bodies underscore the need for impactful education for professionals seeking to enroll in post-graduate programs and associated professional roles.

The APRN engages in diagnosing, managing, educating clients on health promotion, disease reduction and prevention, and health maintenance. Post-graduate programs are impactful in designing and innovating effective patient care models, implementing evidencebased practice, and influencing health policies at various levels (Edwards, Coddington, Erler 
\& Kirkpatrick, 2018). Under the above precedents, this writer opines that there has never been a time than now in the history of America's healthcare when the nation has needed advanced practice registered nurses with proficiency in individual, population, and public health. The pursuit for higher education in such respects aligns with healthcare goals enshrined within the mission and vision of various professional bodies and the Institute of Medicine. Further, there are no questions about the competencies and abilities of the APRN in leading and providing care, promoting overall wellbeing, and improving caregiving situations (Federizo, Shullick \& Witkop, 2018; Edwards, Coddington, Erler \& Kirkpatrick, 2018; Popejoy et al., 2017). Therefore, this inquiry has centered on whether newly graduated APRNs need post-graduate residency training to attain and fulfill the role of providing patient care to a great competency. There are supporting works of literature that advocate for APRNs post-graduate residency training to be at par with other practicing disciplines.

\section{Assessment of the Phenomena}

Well-prepared APRNs are experts in providing effective care management to the patients or clients entrusted into their care. APRNs possess a diverse range of professional skills to address healthcare social factors within their practice setting. These practices setting may include mental health, substance abuse treatment, or addressing acute and chronic care needs in the entirety of their professional practice. However, despite the acquired competency, there arises the need for APRNs to elevate their training to a standard that provides optimum patients outcomes and satisfaction. The Institute of Medicine [IOM, 2010], advocates residencies for new Nurse Practitioners (NPs) among policymakers, stating that nursing doctorate preparation for NPs produces the prospect of considering residency programs within the paradigm of DNP programs. Guaranteeing access to high-quality, effective expert care is one of the core competencies of the DNP (American Association of Colleges of Nursing [AACN], 2006). 
Post-graduate residency programs have evolved over the years. These residency programs have dominated other scientific disciplines such as medicine and surgery. The Institute of Medicine (2010), writing about nursing's future, posited that residency programs would increase proficiencies of NPs and boost patient care outcomes in all levels of healthcare and among all nurses' levels in practice (Painter, Sebach \& Maxwell, 2019). This investigator intends to support, with available literature works, that the NP residency program is necessary to a distinctive NP clinical specialization(s) and that policies that strengthen DNP NP residency training are warranted.

\section{Historical and Societal Perspective}

The historical and societal perspectives of Nurse Practitioners' graduate residency programs are somewhat clouded. There have not been any requirements for Nurse Practitioners to undergo residency training before practice until recently. Residencies for Nurse Practitioners have been a part of the curriculum, which stipulates clinical training and competencies. The American Association of Nurse Anesthetists (AANA) and the National Organization for Clinical Nurse (NOCN) specialists recently identified the DNP degree as an entry-level for the NP role (Edwards, Coddington, Erler \& Kirkpatrick, 2018). This position poses a challenge to academic nursing to develop coherent curriculum alignment standards and accreditation principles for DNP NP programs. However, what agrees is that there is a high worth of DNP in refining the United States health care system. A fundamental factor that has hampered training is the scarcity of adequately equipped clinical sites to provide the highest practice level.

Historically, few institutions offer residencies where tutors expect top-grade clinical training and advanced clinical practice resulting in top-level proficiency and excellence (Harper, McGuiness \& Johnson, 2017). There have been historical proposals for nurse residency programs. These include but are not limited to NPs practicing to the expanded 
scope of their professional education and training; NPs attaining advanced levels of education and expertise through an enhanced education system that facilitates continuous academic progression; NPs cooperating with physicians and other allied healthcare providers in remodifying healthcare status in the US. There exist a societal perspective that appeals to nursing accrediting bodies, the federal government, and health care bodies to back nurses' transition to practice (nurse residency) after they have finished a pre-licensure, an advanced practice degree program, or when they are transitioning into specialized clinical practice roles (Harper, McGuiness \& Johnson, 2017). There have also been calls for funding nurse residencies in rural and other underserved regions of the United States. The Institute of Medicine (2010) called for support to nurse residencies' growth and sustainability across all practice settings, stating that residencies would bolster clinical competencies and boost patient outcomes in all healthcare settings among all nursing practice levels.

\section{Incidence and Prevalence}

While some states require transition to practice hours, post-graduate residency programs' prevalence is nearly non-existent in some areas, and citadels of learning in the advanced nursing profession do not call for compulsory post-graduate residency training. However, as the full practice provision has gained traction, several states have started to expedite the NP statutes and regulations affecting the transition to practice requirements. The statutory obligations underpin the demand for additional support, guidance, and supervision in NP practice's index year(s) (Martsolf, Nguyen, Freund \& Poghosyan, 2017). Harper, McGuiness \& Johnson (2017) posit that a post-graduate residency training that offers a minimum of one year of well-organized, intensive education and training for APRNs shall set the stage for a progressive clinical education environment that supports the change from the academic program and newly graduated NPs to expert clinical practice at the advanced level. 
Residency requirements construed as a facet of the DNP program can also function as the foundation of fostering and integrating DNP Essential VIII, expert clinical practice, other essentials, and fortifying the educational ideals of DNP programs preparing NPs (Harper, McGuiness \& Johnson, 2017). According to the above study, clinical training confers primary care, preventive care, transitional care, chronic care management knowledge, and skills to APRNs for boosting healthcare access and alleviating the primary care shortage. In the US, specialty-based post-graduate NP residencies exist in some states such as Texas, Florida, and New York. A study by Martsolf, Nguyen, Freund \& Poghosyan (2017) highlights that formal post-graduate programs for NP in the US amount to 68, whereby 26 offer residency programs. Mainly, post-graduate nurse practitioner residencies involve specialties like neurology, emergency medicine, palliative care, and oncology (Danaworth, 2017; Alencar et al., 2018; Dahlin, Wholihan \& Johnstone-Petty, 2019; Gaudio \& Borenzstein, 2018; Haderman \& Hough, 2017). Although each program has specific acceptance criteria, resources, and learning strategies, there is a need to establish that postgraduate residency programs assist novice nurse practitioners in advancing patient care outcomes.

\section{Healthcare Cost}

The overall healthcare cost for graduate medical education is enormous. While residency exemplars currently exist for NPs, physical therapists, dentists, and other allied healthcare disciplines, residency education roots stem from medicine. The centers for Medicare and Medicaid provide the most significant funding for graduate medical education. A landmark investigation by Eden, Berwick, \& Wilensky (2014) reports that financing for graduate medical education supersedes $\$ 15$ billion yearly. The funding involves Medicare allocations of $\$ 9.7$ billion, state Medicaid allocations of $\$ 3.9$ billion, and discretionary budget allocation through the Veterans Health Affairs. The Defense Department contributes \$1.4 
billion. Besides, some US states give graduates of medical education financial assistance through state-facilitated programs, such as student loan repayment initiatives to mitigate health workforce scarcity. The Health Resources Services Administration offers approximately $\$ 0.5$ billion through a few graduate medical education programs concentrating on specialized children's healthcare facilities and loan repayment. In 2012, graduate medical education financing through hospital Medicare payments for nursing and allied health education programs totaled \$270 million (Harper, McGuiness \& Johnson, 2017).

According to the HHS, Health Resources Services Administration spent \$67 million in 2013 on nursing education (Harper, McGuiness \& Johnson, 2017). The Center for Medicare and Medicaid Services (CMS) is currently giving financial allocations to five suitable hospital facilities nationwide for the realistic cost of offering clinical training to APRN students from 19 institutions. The clinical training has boosted the number of NPs in these 19 institutions by about $23 \%$ compared with other NP programs nationally (Harper, McGuiness \& Johnson, 2017). The CMS pays the hospitals for the training costs for APRN students. The clinical training offers APRNs primary, preventive, transitional, chronic care management knowledge and skills to boost access and allay the persisting primary care shortage. According to Martsolf, Nguyen, Freund \& Poghosyan (2017), the average postgraduate nurse practitioner residency or fellowship program lasts between 12 and 24 months, and facilities offer residency programs on a full-time basis, with competitive salaries and compensation. The salaries average $\$ 50,000$ to $\$ 60,000$, with the highest being $\$ 100,000$.

\section{Summary}

Systemic post-graduate residency programs exist in various healthcare disciplines except for advanced nursing practice roles (Mounayar \& Cox, 2020). However, healthcare policies such as the ACA act have resulted in higher patient volumes, thereby burdening the limited healthcare workforce in society. Studies demonstrate that as professionals seek to 
increase the accessibility of healthcare, APRNs possess valuable skills for achieving patient outcomes. For instance, APRNs provide excellent and high-quality primary care comparable to physicians in managing common and chronic medical problems (Carranza, Munoz \& Nash, 2021). Nonetheless, there is a backdrop in expanding the roles and scope of practice of available NPs in meeting the escalating healthcare demand. This gap gets accentuated by the rising prevalence of aging in society, increased number of insured individuals, shortages in primary care physicians, and the American population's growth. While clinical competency and skills are key for a well-equipped and DNP-prepared nurse, the implementation of postgraduate residency programs has remained a thorny issue as the proposition has met strong support and criticism in equal measure. National bodies have supported the implementation of the DNP requirement for APRNs, which raises the challenge of developing clinical competencies and preparing eligible candidates adequately as they aspire to fill challenging roles in diverse patient care settings. However, there is support from NP residency graduates that attest to APRNs' importance in acquiring post-graduate residency training. While extensive outcome studies are currently not available currently, there is evidence that postgraduate residency programs or training increase nurse practitioners' clinical expertise and outcome.

This study demonstrates that post-graduate residency programs are worth exploiting to help new graduate nurse practitioners realize set patient outcomes. This study anticipates that post-graduate residency training among new graduate nurse practitioners helps advance patient outcomes, and such gains shall motivate the implementation of such residency programs across all states. The PICOt question in this study entails, "In newly graduate Nurse Practitioners $(\mathrm{P})$, does post-graduate residency program (I), compared to no post-graduate residency program $(\mathrm{C})$, help improve clinical outcome $(\mathrm{O})$, within 1 year $(\mathrm{t})$ ?" 


\section{Literature Review}

\section{Introduction of PICOt Question}

Despite the call and growth of nurse practitioner residency programs, there still exists the need for research to show its efficacy regarding job satisfaction, clinical competencies, and patients' satisfaction. There still exist many uncertainties about the optimal method to achieve a desirable post-graduate residency program for nurse practitioners to maximize an optimum health outcome. Efforts to find evidence-based answers have given rise to substantial clinical inquiries. Although many studies have examined the correlation between post-graduate residency programs for NPs and clinical competency, patient satisfaction, and job satisfaction, the utility of promoting post-graduate residency programs in new graduate nurse practitioners to improve clinical outcomes in the primary care setting remains ambiguous. The focus of general nurse practitioners' education has been on providing advanced roles, knowledge, competencies, and skills to address and treat acute and chronic problems presented by the patients, families, and communities and, for the most part, does not address post-graduate residency program training.

The problem, intervention, comparison, outcome, and time (PICOt) is a framework used to generate a clinical question that guides the healthcare practitioner in finding the needed evidence to answer a perplexing clinical question. $\mathrm{P}$ denotes the population affected by the disease, the letter I represents the interventions or issues of interest, C signifies comparative interventions, $\mathrm{O}$ indicates the outcome of interest, and $\mathrm{t}$ stands for the time to achieve the result. Using these parameters as a guide, the researcher utilized databases to guide the keyword search for evidence to fill the research gap. The clinical question that this study seeks to answer is: In newly graduate nurse practitioners $(\mathrm{P})$, does post-graduate residency program (I), compared to no post-graduate residency program (C), help improve clinical outcome $(\mathrm{O})$ within 1 year $(\mathrm{t})$ ? 
The databases utilized for this clinical inquiry include CINAHL, EBSCO, PubMed, Medline, Google Scholar, Nursing Journals, and the Cochrane Library. The keywords included: post-graduate residency programs for nurse practitioners, effects of post-graduate residency programs on nurse practitioners, the clinical outcome of post-graduate residency programs on nurse practitioners. The development of search phrases involved the use of Boolean operators. The search phrases involved "post-graduate residency programs" AND "nurse practitioners" AND "clinical outcomes" and "effects" AND "post-graduate residency programs" AND "newly graduated" AND "nurse practitioners." These phrases yielded several evidence-based practice (EBP) articles, of which 10 articles were recent and pertinent to the clinical question.

\section{Synthesis of the Literature}

The scope of evidence. The utilization of a post-graduate residency program training to improve new graduate nurse practitioner's clinical outcome continues to evolve as researchers continue to study the effects of such post-graduate training. This study focused on only the keywords specific to the clinical question to find the appropriate literature. The search generated pertinent research articles that emphasized post-graduate residency programs for new graduate NPs. Most of the research selected was limited to recent publications within the past 5 years $(2017-2021)$, except for a few that contained specific information relevant to this study, peer-reviewed studies, full-text articles, and studies published in the English language. Out of the 26 relevant EBP articles identified, 10 were relevant to this white paper. This writer selected, analyzed, and synthesized the articles for inclusion in the literature review. The remaining 16 were either not addressing the clinical question's specific details relevant to provide the necessary answers needed to this study and were not included in the literature review. 
Different divergent opinions exist regarding the utility of post-graduate residency program training to optimize new nurse practitioner clinical outcomes. In a qualitative study by Flinter \& Hart (2017) based on reflective journals from 28 NP graduates working in a primary care NP residency over 8 years, graduates highlighted more excellent clinical proficiency. They also reported a greater clinical proficiency even though the researchers noted no performance appraisals that are part of the NP residency. Future studies of NP residencies should include these performance appraisals to cite residency training's clinical advantages (Flinter \& Hart, 2017). Rugen et al. (2018) evaluated the achievement of competencies among nurse practitioner graduates participating in a residency program implemented in a veteran affairs primary care center. Based on the above study's findings, the participants scored highly in domains such as patient-centered care, interprofessional team collaboration, shared decision-making, and sustained relationships. On Average, the mean self-rating of the participants had a statistically significant improvement $(\mathrm{p}<0.001)$.

A study by Park, Covelli \& Pittman (2021) investigated the impact of post-graduate residency among primary care nurse practitioners. The residency program's presumed benefits were increased role perception, job satisfaction, higher learning and support opportunities, team collaboration, and practice autonomy during the transition process. In the study, nurse practitioners who completed residency reported enhanced practice autonomy, interprofessional collaboration, job satisfaction, and lower turnover than those lacking residency training. Harper, McGuiness \& Johnson (2017) corroborate the above findings stating that new graduate nurse practitioners in primary care settings express that they would benefit from a post-graduate residency training program by gaining extensive clinical experience to prepare them in transitioning and serving in such capacities effectively.

Synthesis of the evidence. Many studies have demonstrated that implementing postgraduate residency programs in new graduate nurse practitioners improves nurse 
competencies, good clinical outcomes, and job satisfaction. The literature search's central focus was to systematically review recent evidence-based articles and research that support the need for the white paper project, which is pertinent to the solution. The author summarized the literature review's salient points under three themes: institutional academic collaboration, post-licensure, and interprofessional collaboration.

Institutional academic collaboration and affiliation. Post-graduate nurse practitioner residency programs should consider having a formal academic partnership or affiliation which supports program components, including curriculum, clinical practice opportunities, didactic sessions, preceptorship, faculty development, evaluation, and additional training. There is a need for a structured transition for new nurse practitioner graduates to achieve clinical proficiency, which increases the necessity for clinical organizations and institutions to affiliate with academic programs (Perron et al., 2019). Academic collaborations and affiliations align with a recent AACN Advancing Healthcare Transformation report highlighting the need to forge a strong partnership between academic nursing and academic health facilities (Greene et al., 2017). Such partnerships promote advances in integrated systems and modern innovation models (Greene et al., 2017). Beneficial collaborations in academia and practice through residencies and similar programs spark and enhance innovative solutions to complex healthcare problems plaguing many settings. Equal partnerships, communication clarity, joint decision-making, and trust between institutions foster an ideal environment for nursing residencies to thrive and impact newly graduated NPs.

Literature by Harper, McGuiness \& Johnson (2017) corroborates that post-graduate residency programs for new nurse practitioners should collaborate with academic institutions to strengthen residency program's rigor. Such partnerships promote the best practice of nursing residency. For instance, as nurse practitioners focus on boosting patient outcomes, 
they need to progress from possessing textbook knowledge to apply clinical skills in healthcare settings, thereby increasing the need for significant collaboration between academic institutions to support residency programs (Perron et al., 2019). Such affiliations contribute to a robust preceptor-resident relationship which is crucial in preparing new nurse practitioners for practice by extending the relationship beyond orientation and additional clinical training (Perron et al., 2019; Slate et al., 2018). For instance, as newly graduated NPs apply their learned knowledge, practical contributions of excellent preceptors through personal reflections, personal training, case studies, and idea mapping should facilitate NPs to gather additional online resources accessed through academic institutions to promote learning during residency (Slate et al., 2018). Therefore, the collaboration between academic institutions and residency-offering institutions is paramount for a newly graduated NP's rounded learning.

Post Licensure. Donaworth (2017) faults existing post-graduate nurse practitioner residencies for having different acceptance criteria, curriculum resources, and learning strategies. A study by Stiansen (2020) corroborates that although the IOM (2010) supports post-graduate nurse practitioner residency programs' implementation to ease practice transition, no consistent formal requirements exist to ensure all new nursing graduates enroll. Post-graduate residencies' quick establishment lacks standardization in their design resulting in operational disparities (Stiansen, 2020). Such concerns demonstrate the need for standard quality of residency programs. This paper's residency program would be post-licensure in a population focus whereby the program shall develop either further expertise in the population or specialty. A structured curriculum is in place that deepens the nurse practitioners' knowledge and experience. In-depth supervision with specified curriculum delivered during clinical rotations in specialty areas shall involve on-site APRN and interprofessional faculty supervision. 
Interprofessional collaboration. Development and implementation of nursing practice residencies align with many of the IOM's (2010) recommendations. Therefore, as post-graduate nursing residencies offer a practical solution to the imminent workforce shortage, there is a burgeoning need to achieve the IOM's recommendations that underscore the need for fostering interprofessional healthcare and analysis (Donaworth, 2017).

According to the literature by Goldsberry (2018), healthcare delivery is increasingly complex and fragmented as issues regarding healthcare reform, healthcare provider specializations, and scarcity of professionals confront the US healthcare system. Since the nursing profession consists of a large healthcare workforce, professionals in the field must be at the forefront in promoting a collaborative approach towards healthcare. Therefore, as modern healthcare transitions from volume-focused to value-focused approaches, interprofessional collaboration is essential. Similarly, the IOM challenges nurse practitioners to reach out to reform healthcare; the professionals must embrace the role of partner in a healthcare team through honing out transformational competencies to meet the challenges of participating in a multidisciplinary team (Goldsberry, 2018). Given that nursing leadership roles are crucial in nursing education to help newly graduated NPs for significant roles in collaborative teams, the above precedents demonstrate that interprofessional educations curriculums should get implemented in various scopes such as residencies.

Rugen et al. (2018) report that interprofessional team collaboration implemented during an NP residency in a primary care facility impacted aspects such as engaging others to manage disagreements, the safe transition of patients among teams, engaging in interprofessional development, and developing a personal identity through explaining roles and responsibilities. Undeniably, the post-graduate residency program's success remains with its coherent fact that is incorporated in interprofessional collaborations. A study by Park, Covelli \& Pittman (2021) supports that post-graduate residency boosts the impact of 
interprofessional collaboration. The interprofessional focus lends itself to demonstrating patient-centered care and improving health outcomes through a collaborative team approach. Residencies get associated with interprofessional team clinical hours. For instance, NP residency resulted in seeking feedback from faculty and team members and appreciating other team members' contributions (Rugen et al., 2018). Patient-centered care gets achieved through improving communication with patients, accommodating and customizing patient care by learning to transcend language, cognitive, functional, or cultural barriers, providing education to empower patients to self-manage chronic conditions, and engaging with health professionals in shared patient-centered problem solving (Rugen et al., 2018).

\section{Theoretical Framework}

Many theories or health models provide a theoretical framework to help understand learning or human behavior changes. These theories help to gain an understanding of the complex relationship between behaviors and outcomes. Comprehending these theories helps promote and conceptualize interventions and help implement needed changes that result in clinical competencies and outcomes. This paper used Benner's Novice to Expert theory as the theoretical framework. Benner developed the theory to underscore the importance of clinical competence. The theory states that expert nurses' top-grade skills, education, and diverse experience help them understand patient care (Graf, Jacob, Twigg, \& Nattabi, 2020). The theory posits that improved practice depends on experience and science, and developing those skills is a long and progressive process. Expertise in any field is a process learned over time.

Benner progresses through five distinctive stages needed for clinical competence. The first stage is the novice stage, where clinical education and behavior are limited and inflexible. The advanced beginner is the second clinical competence stage, whereby practitioners lack in-depth experience. In the third stage, practitioners have acquired some 
competence but lack proficiency. The fourth stage is the proficient stage, where learned experiences get utilized holistically. The final stage, the expert domain, involves practitioners who grasp the situation based on their advanced training, deep knowledge, and experience. The new graduate Nurse Practitioner with post-graduate residency training and knowledge enjoys a higher paying satisfactory job and provides the most exquisite professional care. This paper considered that the theory is relevant to this study's understanding and effectiveness.

In summary, utilizing post-graduate residency programs for new graduate Nurse Practitioners help improve clinical outcome. Following a recommended program will help improve proficiency and competency. When new graduate Nurse Practitioners go through the rigors of a residency program, researchers believe that there is a smooth transition to the Nurse Practitioner role, which is a part of a catalyst for competency and proficiency, leading to limited role confusion, and promotes an increase in retention in the primary care setting. Post-graduate residencies fulfill practical clinical experiences. 


\section{Argument for the Proposed Change}

\section{Introduction}

Despite the significant arguments made in favor of a post-graduate residency training program for new graduate Nurse Practitioners (NP), many uncertainties still exist about the optimal benefits of post-graduate residency programs for new graduate Nurse Practitioners. For instance, literature by Kresten \& El-Bana (2020) evaluated 41 residency program directors in 88 institutions implementing post-graduate residencies for nurse practitioners. In the study, the NP residents noted that the preceptor's high workloads and high cost of implementing the program negatively impacted the programs' implementation. Lack of funding also impacts post-graduate residency programs' success, negatively affecting the NP's motive to pursue residency. A study by Mounayar \& Cox (2020) corroborates that nursing practice is the only discipline that lacks funding and requirements for a systematic clinical residency program or training for advanced practice roles.

Still, in the study by Kresten \& El-Bana (2020), newly graduated NP reported that the preceptor's feedback benefitted them during the transition. Similarly, literature by Park, Covelli \& Pittman (2021) states that nurse practitioners who completed residency reported enhanced practice autonomy, interprofessional collaboration, and lower turnover than those lacking residency training. Therefore, efforts to find an evidence-based answer regarding the cumulative benefit of post-graduate residency among newly graduated nurse practitioners have given rise to substantial clinical inquiries. Although many studies have examined the relationship between post-graduate residency programs for new graduate nurse practitioners and improvement in clinical outcomes, the utility of promoting post-graduate residency training programs across the continuum of nursing professionalism has remained an ongoing concept that needs expansion to facilitate higher coverage so that new NPs can enroll. During the implementation of post-graduate residency programs for newly graduated NPs, this study 
proposes implementing institutional academic collaboration and affiliation, interprofessional collaboration, implementing the residency program in the post-licensure stage, and providing adequate funding for the residency programs.

Facilitating institutional academic collaboration and affiliation is beneficial in several respects. Such collaboration strengthens residency program rigor as such training settings challenge new NPs to work harder and achieve set practice goals (Harper et al., 2017). Institutional collaboration promotes best practice as students learn to transition textbook knowledge into practical clinical skills that advance patient care (Perron et al., 2019). Further, institutional collaboration boosts robust preceptor-resident relationships, fosters effective mentorship, and prepares NPs for future practice (Slate et al., 2018). Focusing on interprofessional collaboration helps new NPs facilitate patient-centered care as the NPs learn to interact, learn, and implement sound care plans derived from several inputs of multidisciplinary team members attending to diverse patients in different healthcare settings. Ideally, interprofessional collaboration during residency promotes a robust team approach during patient care (Park, Covelli \& Pittman, 2021). Interprofessional collaboration during residency helps improve patient outcomes, which is vital in promoting wellbeing. When NPs participating in a residency program learn to collaborate with other professionals, such individuals learn to boost patients' wellbeing during their future practice (Flinter \& Hart, 2017; Park, Covelli \& Pittman, 2021). Learning to set practical goals early in the profession helps new NPs avoid errors, boosting expertise and overall treatment outcomes. This paper supports implementing post-graduate residency in the post-licensure stage. Such an approach is beneficial in developing expertise and deepening knowledge and experience.

\section{Overview}

To buttress the support for the proposed change, this paper, through a scientific inquiry, has generated a clinical question that has guided the principal investigator to find the 
needed evidence to answer that clinical question. Through the process of problem, intervention, comparison, outcome, and time (PICOt), this writer has relied on available evidence to gain insight on the question: In newly graduate Nurse Practitioners $(\mathrm{P})$, does post-graduate residency program (I), compared to no post-graduate residency program (C), help improve clinical outcome $(\mathrm{O})$, within 1 year $(\mathrm{t})$ ? The principal investigator $(\mathrm{PI})$ used an informal interactive engagement questionnaire survey to answer the above question.

In the first step, the PI will give a self-administered questionnaire to survey newly graduated NPs' perceptions towards post-graduate residency programs (see Figure 1). The PI will use Google Surveys, a digital survey platform, to avoid direct contact with participants per the COVID-19 regulations. Before administering the survey, the PI will subject the prepared survey to experts in nursing residency programs and APRNs for validation. The PI will also pilot the survey questions in one healthcare facility in San Diego. Secondly, the PI will visit several primary care facilities in San Diego and meet with the facilities administrators and nursing managers. In the meetings, the PI will explain the survey's purpose and make a compelling case for surveying the facilities' new nursing workforce. Later the PI will seek the facilities' approval to carry out the survey. The PI will seek the nursing managers' assistance in informing the new NPs of the upcoming survey. In the third step, the PI will request to invite newly graduated NPs to the survey. In this step, the PI will communicate with the nursing manager and the communications department to send email invitation links to the newly graduated NPs in the institutions. The PI will the survey via email links since it is convenient for potential respondents to participate online. Since the PI envisions many potential respondents to fill in the survey, the PI will send daily reminders prompts through email to potential respondents to complete the survey. Newly graduated NPs who accept the email invitation to participate in the study shall get redirected to the online survey to fill their responses. Besides the minuscule cost incurred by the principal 
investigator in purchasing stationeries, communication, and mobility, there was no substantial cost incurred.

In the fifth step, the PI will use the survey findings and scientific evidence to make a compelling case for implementing post-graduate residency programs to hospital administrators, novice NPs, legislators, and professional accrediting bodies by making appointments and meeting the respective officials. First, the PI will share the findings with different professional accrediting bodies to demonstrate the existing gap in the continuum of healthcare provision and the perceptions of NPs towards implementing post-graduate residency for newly graduated NPs. The PI will request several meetings with the relevant officials through booking appointments. The rationale for beginning with professional accrediting bodies stems from the bodies' role in being at the forefront of ensuring adequate qualifications and competency among the nursing workforce. After meeting with accrediting bodies officials', the PI will book meetings with the healthcare facility administrators and reveal the study's outcomes. In the meeting, the PI will underscore the value of collaboration between the facility and academic institutions to promote an effective and rigorous residency program for adequate NP role preparation. The PI will seek an appointment with local legislators to inform them of the findings of the study while aiming at inspiring them to advocate for more funding to healthcare and upgrading current healthcare status by incorporation of new policies such as post-graduate NP residencies, which researchers have shown to work in literature and per the observations of the survey.

\section{Population}

The population focus entails newly graduate Nurse Practitioners who are yet to start practicing or whose practice experience has been less than 3 months. Those who have started practicing less than 3 months in the survey were taken strictly from primary care settings. In 
the survey, most participants supported the implementation of post-graduate residency programs. While the residencies' primary focus entails NPs, such programs necessitate inputs from other professionals. For instance, the newly graduated nurses need mentorship from qualifies preceptors in the respective specialties.

\section{Process}

This white paper proposes utilizing the Iowa model to support post-graduate residencies for new NPs. Various studies support the Iowa model as a conceptual framework for implementing evidence-based practice changes (Buckwalter et al., 2017; Milner, Zonsius, Alexander \& Zellefrow, 2019; Titler et al., 2001). The Iowa model has six stages. The first stage entails identifying practice questions based on nursing professionals' critical thinking. In this step, this white paper raises a practice question that entails, in newly graduated Nurse Practitioners, does post-graduate residency program, compared to no post-graduate residency program, help improve clinical outcome within 1 year? The question is a product of both practice and knowledge-oriented triggers. Professionals in various nursing facilities must identify the gap highlighted in the question and identify the questions triggers.

As this white paper demonstrates, NPs in primary care facilities need to understand that shortages in the US healthcare workforce increase the need for more NPs to take up advanced roles. However, contrary to various healthcare disciplines that offer post-graduate residencies to ease professionals' transition to higher roles, the nursing field lacks funding and requirements for a systematic clinical residency program or training for advanced practice roles that necessitates the need for change. Under the construct of knowledge triggers, NPs in various primary care facilities should understand that the research question has adequate underpinnings stemming from positional statements from national bodies like AANA, NOCN, and AACN (Painter, Sebach \& Maxwell, 2019; Edwards, Coddington, Erler \& Kirkpatrick, 2018). However, various researchers have highlighted the usefulness of 
implementing a post-graduate residency program for NPs (Flinter \& Hart, 2017; Rugen et al., 2018; Park, Covelli \& Pittman, 2021). After facilities identify the above triggers, facilities arrive at a decision point which is the second step. In this step, committees and administrators decide whether the post-graduate nursing residencies are a priority. Undeniably, the focus on improving patient outcomes and addressing the looming workforce crisis in a healthcare facility generates a fresh impetus of adopting ways that improve the caregiving situation in various hospitals. Therefore, many facilities will decide in favor of the proposed change.

Thirdly, facilities shall form a specific team that aims at developing and implementing specific strategies. The team will involve experienced DNP-NPs from various specialties and representatives from accrediting bodies. The experienced DNP-NPs shall highlight various competencies that new NPs need to develop during residency, collect research evidence on the value of such competencies on impacting patient outcomes, and support the need for implementing residency programs for new NPs. The accrediting bodies' officials will collaborate with academic institutions to highlight evidence of effective residency programs that positively impact the training of new NPs. After assembling evidence, the team will synthesize and critique the available evidence. In the fourth step, the team comes to a second decision point. In this stage, the team will determine the adequacy of the evidence. Bearing the research highlighted in this white paper, the teams may gather a solid evidence base from scientific research supporting post-graduate residencies for NPs.

In the fifth process, the development of sufficient evidence will warrant the implementation of a pilot post-graduate residency program in a facility (Titler et al., 2001). Six processes involving selecting desired outcomes, collecting baseline data, designing practice guidelines based on research evidence, implementing a pilot unit, evaluation, and modification will get implemented during piloting. Under selecting desired outcomes, the team will emphasize excellent patient outcomes. During baseline data collection, experienced 
DNP-NPs will observe new NPs who will get involved during the piloting. The new NPs will fill surveys focusing on their competencies and expectations when working in their respective specialties. When designing evidence-based practice guidelines, the team will use evidence from the baseline data, SWOT analysis, and evidence from similar residency programs implemented in other facilities to tune the program to levels that suit the needs of the new NPs and meets the practice expectations of various specialties. Later, the piloting will roll out for one year, whereby after the period lapses, the team will evaluate the process per the program's expectations. The evaluation process findings will result in modifications of the practice guidelines to promote consistency. In the sixth step, a third decision point gets involved whereby the piloting exercise's success determines the practice change's worth. Since professionals and other stakeholders will collaborate in the piloting process, the pilot residency program's success will result in the institution of post-graduate NP residency programs in a healthcare facility.

After instituting the change, the team will also monitor and analyze the process and outcome data regarding the environment, staff, and costs (Titler, 2001). Under environment, facilities will foster collaboration with different units to implement the residency program. The facility will boost inter-specialty buy-in by organizing in-house meetings and providing assistance to any specialty with resident NP professionals. Under staff outcomes, facilities will foster adequate preceptors and facilitate their role as mentors of new NPs in their new roles. Such facilitation will involve reasonable workloads and allocate enough resources to train the new NPs. In terms of costs, a study by Martsolf, Nguyen, Freund \& Poghosyan (2017) reported that facilities offer residency programs on a full-time basis, with competitive salaries which average $\$ 50,000$ to $\$ 60,000$. Therefore, facilities implementing the residencies will coordinate with financing departments and Medicare to ensure that the residents and their preceptors get compensated accordingly. 


\section{Change Analysis}

After implementing the post-graduate residency program for the newly graduated Nurse Practitioners (NPs), improving clinical outcomes within one year will be measured and analyzed through several metrics. These metrics will entail documenting and analyzing outcomes related to Nurse Practitioner competency and confidence and client satisfaction and outcomes. Measuring Nurse Practitioners' competency and confidence will derive from the individual Nurse Practitioner's mentor's feedback. This mentor will have the role of mentoring and supervising the Nurse Practitioner during the residency program and assess the Nurse Practitioner's change in confidence and competency. This feedback will give the residency program's effect on the Nurse Practitioners.

Measurement and analysis of client satisfaction and outcomes will occur through various techniques. The first technique will involve using a client satisfaction score. These scores will measure the client satisfaction variations using a fundamental question. For instance, the researcher will ask, "How would you rate your experience interacting with our Nurse Practitioner?" the client can give a range of responses such as very unsatisfactory, unsatisfactory, neutral, satisfactory, and very satisfactory. Getting a higher number of positive responses will indicate a desirable impact of implementing the post-graduate residency program for the newly graduated Nurse Practitioners. Secondly, the researchers will utilize direct feedback from the client using various methods, such as in-app client surveys, post-treatment client surveys, and client surveys. In-app client surveys will occur while the client receives care services from the resident Nurse Practitioners. This process shall enable the client to respond immediately to their satisfaction from the Nurse Practitioner's care. After receiving care services from the Nurse Practitioner, the client will receive a post-service survey to indicate their care provision satisfaction. This survey can take various techniques, including live chat and over the telephone. Alternatively, the researchers 
shall use client surveys through email. This technique will enable the researcher to ask the client broader questions concerning the Nurse Practitioners' entire care delivery. The methods' positive responses will promote post-graduate residency program implementation for the newly graduated Nurse Practitioners (NPs).

Thirdly, the researchers will analyze the volunteered feedback from the client. For example, most facilities have provided their clients with surveys to indicate their experience and satisfaction with the care services. The clients fill these surveys without coercion. The researchers will analyze these surveys and determine the appropriateness of implementing a post-graduate residency program for the newly Nurse Practitioners (NPs). Equally, more positive client feedback will promote this residency program's application. 


\section{Discussion}

\section{Barriers and Limitations}

The implementation of post-graduate residency programs for the newly graduated Nurse Practitioners (NPs) is likely to face several limitations and barriers. Lack of a structured curriculum and standardization is the primary limitation in implementing a postgraduate residency program for the newly graduated Nurse Practitioners (NPs). For instance, Donaworth (2017) faulted the current post-graduate nurse practitioner residencies for having different acceptance criteria, curriculum resources, and learning strategies. Stiansen (2020) further supported this claim by affirming that although the IOM (2010) promotes postgraduate nurse practitioner residency programs' implementation to ease practice transition, the lack of consistent formal requirements to ensure all nurses enroll hampers this process. Lack of standardization in the design of post-graduate residency programs further complicates their implementation by causing significant operational disparities.

The second hurdle to implementing post-graduate residency programs for the newly graduated Nurse Practitioners entails the staffing problems in the US healthcare system. Implementing post-graduate residency programs for the newly graduated Nurse Practitioners will require a structured curriculum and in-depth supervision during clinical rotations in the Nurse Practitioners' specialty areas. This process's qualified professionals will involve the APRNs and interdisciplinary care team such as physicians. According to Wheeler, Dewan, Maxwell, Riley \& Stalets (2018), about 50\% of critical care physicians experience workrelated burnout. The same applied to approximately $50 \%$ of all pediatric care providers, including APRNs. Adding more responsibilities such as post-graduate residency programs to an already overstretched healthcare system can result in burnout and negative impacts on healthcare facility operations. This situation limits post-graduate residency programs' implementation for the newly graduated Nurse Practitioners. 
The third barrier to implementing post-graduate residency programs for the newly graduated Nurse Practitioners involves lack of funding. Implementing post-graduate residency will require several activities, such as curriculum development and quality standardization among the US's healthcare facilities. These programs' facilitators, such as experienced DNP-NPs and physicians, will require compensation. The same will apply to the newly graduated Nurse Practitioners undertaking these residency programs. This situation will demand more funding to the already overstretched federal and local governments and agencies such as Medicaid and Medicare, which increases the likelihood of preventing the implementation of post-graduate residency programs for the newly graduated Nurse Practitioners.

\section{Sustainability}

Despite the numerous challenges impeding post-graduate residency programs for the newly graduated Nurse Practitioners, several interventions can sustain this endeavor. The first intervention should involve the healthcare stakeholders such as the government and agencies such as Medicaid and Medicare looking for funds. Having adequate funding will benefit this endeavor in several ways. These funds will support developing the post-graduate residency program curriculum and standardization procedures. This funding will promote public awareness to notify the public of the value of having post-graduate residency programs for newly graduated Nurse Practitioners. The same process will incentivize the prospective Nurse Practitioners to undertake the programs. Funds wiill also compensate these programs' facilitators, such as APRNs and physicians.

The second intervention should involve the government and other healthcare sector stakeholders employing more healthcare workers to reduce US healthcare staffing problems. Enough healthcare staff will allow some experienced DNP-NPs and physicians to mentor and supervise the newly graduated Nurse practitioners in their post-graduate nursing programs 
without affecting their healthcare service delivery. The third intervention to support the freshly graduated Nurse Practitioners' post-graduate residency programs entails developing a practical curriculum and standards. This process will ensure all healthcare facilities follow similar learning procedures and examination tools for the post-graduate residency programs. This solution will solve the inconsistency issues, as highlighted by Stiansen (2020). 


\section{Dissemination and Application to the DNP Essentials}

\section{Dissemination}

Dissemination of the White Paper's findings will involve several activities and processes. The first activity will include submitting the White Paper manuscript to relevant nursing journals in the US. This process will occur after obtaining the necessary academic approvals. The second activity will involve printing the objectives and findings of this White Paper and presenting them to the appropriate stakeholders, such as nursing accrediting bodies, healthcare providers, and local legislators. Explaining the objectives and findings to the nursing accrediting bodies will simplify implementing the post-graduate residency program for the newly graduated Nurse Practitioners through curriculum development and standardization. Presenting the findings and objectives to the healthcare providers will enable them to understand these programs' value and motivate them to advocate for these programs. Providing the White Papers aims and findings to the local legislators will allow them to formulate the appropriate policies and legislation required to implement the newly graduated Nurse Practitioners' post-graduate residency programs.

\section{Application to the DNP Essentials}

According to AACN (2006), DNP essentials detail the curricular aspects and skills needed by all Doctor of Nursing Practitioner (DNP) programs. The essentials echo the IOM's sentiments to re-conceptualize nursing education. This re-conceptualization addresses the increasing complexities requirements of a modern healthcare model. The DNP essentials consist of eight foundation competencies vital to all the DNP graduates irrespective of their specialty. This Master Paper fulfilled four foundational competencies suitable to postgraduate nurse practitioners.

Essential 1: Scientific Underpinnings for practice. The emergence of nursing theories has expanded nursing significantly. A sufficient understanding of these theories 
provides a suitable ground for advanced nursing practice. Degree in DNP lays the required basis for nursing graduates to integrate nursing knowledge with various sciences, including analytical and psychological ones AACN, 2006). The underpinning of practice also highlights the essence of using scientific concepts to enhance and evaluate care delivery and patient outcomes. This role requires the DNP graduates to integrate their nursing information with organizational and biophysical sciences.

The White Paper has fulfilled this essential in several ways. The paper advocates for post-graduate residency programs for newly graduated Nurse Practitioners. Having Nurse Practitioners undergo these residency programs will improve their confidence, competence, and preparedness to effectively provide specialized care and improve patients' outcomes in their specialty areas. After graduation from advanced nursing practice programs, entry into practice represents a transition from theory to practice. Similarly, this situation represents a situation of transiting from student life to professional practice. After introducing the Affordable Care Act, the number of people seeking healthcare has increased significantly (Griffith, Evans \& Bor, 2017). Unfortunately, this increase did not coincide with an increase in healthcare staffing. This situation has increased the burden of providing care among care providers such as APRNs.

Newly graduate NPs do not get forced to get into professional practice immediately after graduation. While this step is vital in solving the burden of providing healthcare, it impacts many adverse impacts on the Nurse practitioners and patient outcomes. For instance, these graduates are bundled with significant specialty roles without adequate preparation, making some of them quit or experience significant burnouts. This result ends up influencing care provision and patient outcomes. The White Paper fulfills this essential by proposing a chance for newly graduate Nurse Practitioners to overcome the confidence and competence 
issues hampering their nursing knowledge integration with organizational, biophysical, psychological, and analytical sciences.

\section{Essential II: Organizational and Systems Leadership for Quality Improvement.}

Nursing graduates from doctorate programs make significant contributions to nursing science. This contribution occurs when the graduates evaluate, translate, and disseminate information or research outcomes into practice. Essential II underscores DNP graduates' role in integrating nursing science into clinical practice to solve the complex healthcare needs and wants (AACN, 2006). Nursing science's assimilation into clinical practice requires the DNP graduates to possess several skills, including developing clinical practice strategies, developing evidence-based techniques, and appraising practice outcomes.

The White paper fulfills essential II in several ways by proposing post-graduate residency programs for the newly graduated NPs, which has several outcomes. For instance, residency programs will enable the newly graduated NPs to work under APRNs and physicians. These professionals will mentor, assess and evaluate the clinical capabilities of the freshly graduated NPs. Working under these professionals will enable the NPs to evaluate their practical abilities, revisit their nursing curriculum and ask for help. Secondly, these programs will allow the NPs to experience the clinical environment of specialty before joining. This exposure will enable the NPs to have a mental and physical preparedness of the working environment and make the necessary adjustments to fit in. This 'grace period' will allow the NPs to gain the required competency, expertise, and courage to work on their clinical specialty areas.

These aspects amount to improved nursing science capabilities by examining and disseminating nursing science into clinical practice. Post-graduate residency programs also allow the newly graduated nursing practitioners to practice formulating clinical practice 
techniques, design evidence-based solutions and appraise the practice outcomes. This process adds to the expertise, competency, and courage of the NPs to perform such activities after completing their residency programs. The integration of nursing knowledge and practice to solve current and emerging healthcare needs requires utmost finesse to formulate nursing practice guidelines, develop evidence-based clinical strategies, and evaluate nursing practice outcomes. This process forms the backbone of essential II, which the White Paper fulfills by proposing post-graduate residency programs for the newly graduated nursing practitioners.

\section{Essential VI: Inter-Professional Collaboration for Improving Patient and}

Population Health Outcomes. IOM (2010) advocates for team-based care to improve patients' wellbeing and safety. Essential VI equips DNP graduates with the necessary skills to lead inter-professional teams and enhance care delivery. This leadership should scrutinize multi-dimensional practice and systems problems through efficient collaboration and effective communication techniques (AACN, 2006). DNP graduates should take an active role in the formulation and implementation of care delivery standards, practice models, and evidence-based interventions. The main hurdle to fulfill essential VI among the newly graduated nurse practitioners lies in the lack of adequate preparedness, evaluation and guidance before joining their specialty areas. Implementing post-graduate residency programs for the newly graduated NPs will solve this issue in several ways. For instance, the programs will enable the newly graduated NPs to evaluate and improve their practical skills by working with supervisors and mentors, such as APRNs and physicians. The efficient working relationships among the newly graduated NPs shall enhance their clinical skills and communication and collaboration skills. These capabilities form the primary basics of leading inter-professional teams. The White Paper advocates for post-graduate residency programs for the newly graduated NPs to improve their communication and collaboration expertise hence fulfilling Essential VI. 
Essential VIII: Advanced Nursing Practice. This essential emphasizes the doctor of nursing practice's primary role to enhance patient outcomes (AACN, 2006). DNP graduates fulfill this role by improving their system thinking, clinical judgments, and evidence-based care. The essential underscores the value of conducting comprehensive needs assessments, guiding patients having complex situational analysis, and mentoring other nurses. The White Paper fulfills this essential in various ways. For instance, the paper proposes implementing post-graduate residency programs for newly graduated Nurse Practitioners. These programs shall equip the NPs with the necessary courage and expertise to work with patients requiring specialty services by working under APRNs and physicians. These programs will also allow newly graduated NPs to revisit areas that they could not have grasped well during their residency programs. Secondly, the programs will enable the newly graduate NPs to understand their specialty's practical environment. This process will allow the newly graduate NPs to find the required capacity for full-service delivery in their specialty by asking pertinent questions, engaging with their mentors, and seeking the correct information. Such steps shall enable the nurse practitioners to gain the right competency, courage, and expertise before practicing. Allowing NPs to have individual personal and mental preparedness before transiting into practice shall reduce their anxiety and frustrations. Cases of low turnout and turnover rates among the newly graduated NPs shall decrease significantly. Working with NPs with the right attitude, courage and expertise shall translate into improved patient outcomes. This atmosphere will create an effective environment for NPs to strengthen their system thinking, clinical judgments, and evidence-based care. 


\section{Concluding Statement}

\section{Reflections on Growth in Advanced Practice Nursing Role}

No one ever said it would be easy, but it has been worth it. In the past four years, I have learned so much about myself and my innate ability to connect with others in an intimate but professional manner. The knowledge and skills I have obtained in my quest to complete the DNP program cannot be tallied. Earning a DNP posits that I have acquired the skills necessary to become an advanced practitioner, adept at treating the complex and voluminous mental and physical issues that plague our society. Therefore, becoming a member of this select group dedicated to improving the lives of others is a true honor.

The journey was filled with obstacles I did not think I would overcome. Each time, I challenged myself to conquer those qualms and overcome the persistent fears that threatened to hinder my success. As I reflect on those moments, I realize their purpose was to strengthen my resolve and remind me of the rigorous work and sacrifices essential to achieving my goal. I stand here as a testament to what can be accomplished through faith in God, hard work, and perseverance.

Although I am at the end of this program, my journey has just begun. There is still so much to learn and improve upon. My thirst for knowledge is a quality that will never cease to exist. I will confront each hurdle that lies ahead with an unremitting desire to play a vital role in healthcare advances. I understand the significant amount of responsibilities bequeathed to me, and I welcome the chance to meet and exceed those expectations.

It has truly been an honor to be a part of such a distinguished program. I still have my occasional doubts and fears, but fundamentally, I trust the skills I have acquired, knowing my genuine care for the wellbeing of others will always be the fuel that drives me. I promise to always practice with truth and integrity. I pledge to continually champion the fight for 
independence merited in the role of advanced practice nursing. Educating and serving as a mentor for future nurses will be a focal part of my future in this endeavor. I can never repay all the rewards nursing has given me. My only hope is to ensure that the future of nursing will be better than the past. As I start this new endeavor, I am reminded of a quote by John Green, "Destiny is not something that happens all at once it's something that happens only in retrospect." 


\section{References}

Abraham, C. M., Norful, A. A., Stone, P. W., \& Poghosyan, L. (2019). Cost-Effectiveness of Advanced Practice Nurses Compared to Physician-Led Care for Chronic Diseases: A Systematic Review. Nursing Economics, 37(6), 293-305. Retrieved from: https://search.proquest.com/openview/5bcfdfc2492be2665b28dad767ab9402/1?pqorigsite $=$ gscholar $\& \mathrm{cbl}=30765$

Alencar, M. C., Butler, E., MacIntyre, J., \& Wempe, E. P. (2018). Nurse Practitioner Fellowship: Developing a Program to Address Gaps in Practice. Clinical journal of oncology nursing, 22(2), 142-145. https://doi.org/10.1188/18.CJON.142-145

American Association of Colleges of Nursing (2006). The essentials of doctoral education for advance nursing practice. Washington, DC Author. Retrieved from: https://www.aacnnursing.org/Portals/42/Publications/DNPEssentials.pdf

American Association of Colleges of Nursing (2006). The essentials of doctoral education for advance nursing practice. Washington, DC: Author. Retrieved from: https://www.aacnnursing.org/Portals/42/Publications/DNPEssentials.pdf

Carranza, A. N., Munoz, P. J., \& Nash, A. J. (2020). Comparing quality of care in medical specialties between nurse practitioners and physicians. Journal of the American Association of Nurse Practitioners, 33(3), 184-193. https://doi.org/10.1097/JXX.0000000000000394

Courtemanche, C., Marton, J., Ukert, B., Yelowitz, A., \& Zapata, D. (2018). Effects of the Affordable Care Act on health care access and self-assessed health after 3 years. INQUIRY: The Journal of Health Care Organization, Provision, and Financing, 55, 0046958018796361. https://doi.org/10.1177/0046958018796361 
Dahlin, C., Wholihan, D., \& Johnstone-Petty, M. (2019). Palliative APRN fellowship guidelines - a strategy for quality specialty practice: Report of the HPNA APRN fellowship council (TH300). Journal of Pain and Symptom Management, 57(2), 363. https://doi.org/10.1016/j.jpainsymman.2018.12.029

Donaworth, S. L. (2017). Making the case for adult-gerontology critical care nurse practitioner fellowships. OJIN: The Online Journal of Issues in Nursing, 22(3). Retrieved from: http://ojin.nursingworld.org/MainMenuCategories/ANAMarketplace/ANAPeriodicals /OJIN/TableofContents/Vol-22-2017/No3-Sep-2017/Articles-Previous$\underline{\text { Topics/AdultGerontology-Critical-Care-Nurse-Practitioner-Fellowships.html }}$

Eden, J., Berwick, D., Wilensky, G., Committee on the Governance and Financing of Graduate Medical Education, Board on Health Care Services, \& Institute of Medicine (Eds.). (2014). Graduate Medical Education That Meets the Nation's Health Needs. National Academies Press (US).

Edwards, N. E., Coddington, J., Erler, C., \& Kirkpatrick, J. (2018). The Impact of the Role of Doctor of Nursing PracticeNurses on Healthcare and Leadership. Medical Research Archives, 6(4). Retrieved from:

https://scholar.google.com/scholar_url?url=https://esmed.org/MRA/mra/article/downl $\underline{\text { oad}} / 1734 / 1794 \& h l=e n \& s a=T \& o i=g s b-$ ga\&ct=res\&cd=0\&d=255722062376631080\&ei=0qpYYNHoGZD_mAGb8ojQBg\&s cisig=AAGBfm1eZOHhCzx3VXFn5zz99VfJTt5lyQ

Faraz A. (2017). Novice nurse practitioner workforce transition and turnover intention in primary care. Journal of the American Association of Nurse Practitioners, 29(1), 2634. https://doi.org/10.1002/2327-6924.12381 
Faraz A. (2019). Facilitators and barriers to the novice nurse practitioner workforce transition in primary care. Journal of the American Association of Nurse Practitioners, 31(6), 364-370. https://doi.org/10.1097/JXX.0000000000000158

Flinter, M., \& Hart, A. M. (2017). Thematic elements of the post-graduate NP residency year and transition to the primary care provider role in a Federally Qualified Health Center (FQHC). Journal of Nursing Education \& Practice, 7(1), 95-106. https://doi.org/10.5430/jnep.v7n1p95

Gaudio, F. G., \& Borensztein, R. (2018). An Emergency Medicine Residency for Nurse Practitioners: The New York Presbyterian-Weill Cornell Medicine Experience. Advanced emergency nursing journal, 40(2), 119-126. https://doi.org/10.1097/TME.0000000000000186

Goldsberry J. W. (2018). Advanced practice nurses leading the way: Interprofessional collaboration. Nurse education today, 65, 1-3. https://doi.org/10.1016/j.nedt.2018.02.024

Graf, A. C., Jacob, E., Twigg, D., \& Nattabi, B. (2020). Contemporary nursing graduates' transition to practice: A critical review of transition models. Journal of clinical nursing, 29(15-16), 3097-3107. https://doi.org/10.1111/jocn.15234

Greene, M. Z., FitzPatrick, M. K., Romano, J., Aiken, L. H., \& Richmond, T. S. (2017). Clinical fellowship for an innovative, integrated BSN-PhD program: An academic and practice partnership. Journal of professional nursing: official journal of the American Association of Colleges of Nursing, 33(4), 282-286.

https://doi.org/10.1016/j.profnurs.2016.12.001 
Griffith, K., Evans, L., \& Bor, J. (2017). The Affordable Care Act reduced socioeconomic disparities in health care access. Health Affairs, 36(8), 1503-1510. https://doi.org/10.1377/hlthaff.2017.0083

Hardeman, P., \& Hough, R. (2017). Integration of Advanced Practice Clinicians in Neurology Practices. JAMA neurology, 74(8), 894-895. https://doi.org/10.1001/jamaneurol.2017.1382

Harper, D. C., McGuinness, T. M., \& Johnson, J. (2017). Clinical residency training: Is it essential to the Doctor of Nursing Practice for nurse practitioner preparation?. Nursing outlook, 65(1), 50-57. https://doi.org/10.1016/j.outlook.2016.08.004

Institute of Medicine (2010). The Future of Nursing: Leading Change, Advancing Health. Washington, DC: The National Academies Press. https://doi.org/10.17226/12956

Iowa Model Collaborative, Buckwalter, K. C., Cullen, L., Hanrahan, K., Kleiber, C., McCarthy, A. M., Rakel, B., Steelman, V., Tripp-Reimer, T., Tucker, S., \& Authored on behalf of the Iowa Model Collaborative (2017). Iowa Model of Evidence-Based Practice: Revisions and Validation. Worldviews on evidence-based nursing, 14(3), 175-182. https://doi.org/10.1111/wvn.12223

Kesten, K. S., \& El-Banna, M. M. (2020). Facilitators, barriers, benefits, and funding to implement post-graduate nurse practitioner residency/fellowship programs. Journal of the American Association of Nurse Practitioners, 10.1097/JXX.0000000000000412. Advance online publication. https://doi.org/10.1097/JXX.0000000000000412

Martsolf, G. R., Nguyen, P., Freund, D., \& Poghosyan, L. (2017). What we know about postgraduate nurse practitioner residency and fellowship programs. The Journal for Nurse Practitioners, 13(7), 482-487. https://doi.org/10.1016/j.nurpra.2017.05.013 
McCauley, L. A., Broome, M. E., Frazier, L., Hayes, R., Kurth, A., Musil, C. M., Norman, L. D., Rideout, K. H., \& Villarruel, A. M. (2020). Doctor of nursing practice (DNP) degree in the United States: Reflecting, readjusting, and getting back on track. Nursing outlook, 68(4), 494-503. https://doi.org/10.1016/j.outlook.2020.03.008

Meissen, H. (2019). Nurse practitioner residency and fellowship programs: The controversy still exists. Journal of the American Association of Nurse Practitioners, 31(7), 381383. https://doi.org/10.1097/JXX.0000000000000255

Milner, K., Zonsius, M., Alexander, C., \& Zellefrow, C. (2019). Doctor of Nursing Practice Project Advisement: A Roadmap for Faculty and Student Success. The Journal of nursing education, 58(12), 728-732. https://doi.org/10.3928/01484834-20191120-09

Mounayar, J., \& Cox, M. (2020). Nurse Practitioner Post-Graduate Residency Program: Best Practice. The Journal for Nurse Practitioners. https://doi.org/10.1016/j.nurpra.2020.10.023

National Organization of Nurse Practitioner Faculties (NONPF) (2015). The Doctorate of Nursing Practice NP Preparation: NONPF Perspective 2015. Retrieved from: https://cdn.ymaws.com/www.nonpf.org/resource/resmgr/DNP/NONPFDNPStatement $\underline{\text { Sept2015.pdf }}$

Nelson R. (2017). Do NPs Need Post-graduate Residencies?. The American journal of nursing, 117(3), 19-20. https://doi.org/10.1097/01.NAJ.0000513280.61011.57

Norful, A. A., Swords, K., Marichal, M., Cho, H., \& Poghosyan, L. (2019). Nurse practitioner-physician comanagement of primary care patients: The promise of a new delivery care model to improve quality of care. Health care management review, 44(3), 235-245. https://doi.org/10.1097/HMR.0000000000000161 
Painter, J., Sebach, A. M., \& Maxwell, L. (2019). Nurse practitioner transition to practice: development of a residency program. The Journal for Nurse Practitioners, 15(9), 688691. https://doi.org/10.1016/j.nurpra.2019.05.003

Park, J., Faraz Covelli, A., \& Pittman, P. (2021). Effects of completing a post-graduate residency or fellowship program on primary care nurse practitioners' transition to practice. Journal of the American Association of Nurse Practitioners, 10.1097/JXX.0000000000000563. Advance online publication.

\section{https://doi.org/10.1097/JXX.0000000000000563}

Perron, T., Gascoyne, M., Kallakavumkal, T., Kelly, M., \& Demagistris, N. (2019). Effectiveness of nurse residency programs. Journal of Nursing Practice Applications \& Reviews of Research, 9(2), 48-52. https://doi.org/10.13178/jnparr.2019.09.02.0908

Poghosyan, L., Liu, J., \& Norful, A. A. (2017). Nurse practitioners as primary care providers with their own patient panels and organizational structures: A cross-sectional study. International journal of nursing studies, 74, 1-7.

https://doi.org/10.1016/j.ijnurstu.2017.05.004

Popejoy, L., Vogelsmeier, A., Galambos, C., Flesner, M., Alexander, G., Lueckenotte, A., ... \& Rantz, M. (2017). The APRN role in changing nursing home quality: the Missouri quality improvement initiative. Journal of nursing care quality, 32(3), 196-201. https://doi.org/10.1016/j.jamda.2017.05.027

Rugen, K. W., Dolansky, M. A., Dulay, M., King, S., \& Harada, N. (2018). Evaluation of Veterans Affairs primary care nurse practitioner residency: Achievement of competencies. Nursing outlook, 66(1), 25-34.

https://doi.org/10.1016/j.outlook.2017.06.004 
Slate, K. A., Stavarski, D. H., Romig, B. J., \& Thacker, K. S. (2018). Longitudinal Study Transformed Onboarding Nurse Graduates. Journal for nurses in professional development, 34(2), 92-98. https://doi.org/10.1097/NND.0000000000000432

Stiansen, C. (2020). Analysis of current post graduate nurse practitioner residency programs (Doctoral dissertation, Rutgers University-School of Nursing-RBHS). https://doi.org/doi:10.7282/t3-bvpj-p785

Titler, M. G., Kleiber, C., Steelman, V. J., Rakel, B. A., Budreau, G., Everett, L. Q., Buckwalter, K. C., Tripp-Reimer, T., \& Goode, C. J. (2001). The Iowa Model of Evidence-Based Practice to Promote Quality Care. Critical care nursing clinics of North America, 13(4), 497-509. https://doi.org/10.1016/S0899-5885(18)30017-0

Wheeler, D. S., Dewan, M., Maxwell, A., Riley, C. L., \& Stalets, E. L. (2018). Staffing and workforce issues in the pediatric intensive care unit. Translational pediatrics, 7(4), 275. https://dx.doi.org/10.21037\%2Ftp.2018.09.05 
Appendix

\section{Figure 1}

Survey on utilizing post-graduate residency for newly graduated nurse practitioners

\section{A SURVEY ON UTILIZING POST-GRADUATE RESIDENCY FOR NEWLY GRADUATED NURSING PRACTITIONERS}

\section{Socio-Demographic Characteristics}

1. Age. (Enter your age below in years)

2. Sex (Select your sex below)

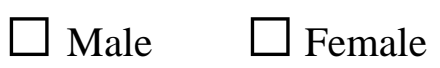

\section{Survey Questions}

(Click on 'Choose an item' menu under each prompt to select your preferred response)

1. All Nurse Practitioner programs should require a one-residency.

\section{Choose an item.}

2. I was confident in delivering patient care without attending a residency program.

\section{Choose an item.}

3. If a residency were available in my program, I would have participated.

\section{Choose an item.}

4. I believe a residency program would give me the confidence and knowledge to deliver better patient care

\section{Choose an item.}

5. Participation in a residency program would improve patient outcomes for Nurse Practitioners. 
Choose an item.

6. Post-graduate Nurse Practitioner programs should remain optional. Choose an item.

7. I cannot afford to participate in a one-year residency program.

Choose an item.

8. Clinical residency training is essential for Nurse Practitioners.

Choose an item.

9. Clinical Residency training provides distinctive clinical specializations.

Choose an item.

10. Clinical residency training provides job satisfaction, clinical competencies, and patient satisfaction.

Choose an item. 


\section{Figure 2}

\section{Iowa Model of Evidence-Based Practice to Promote Quality Care}

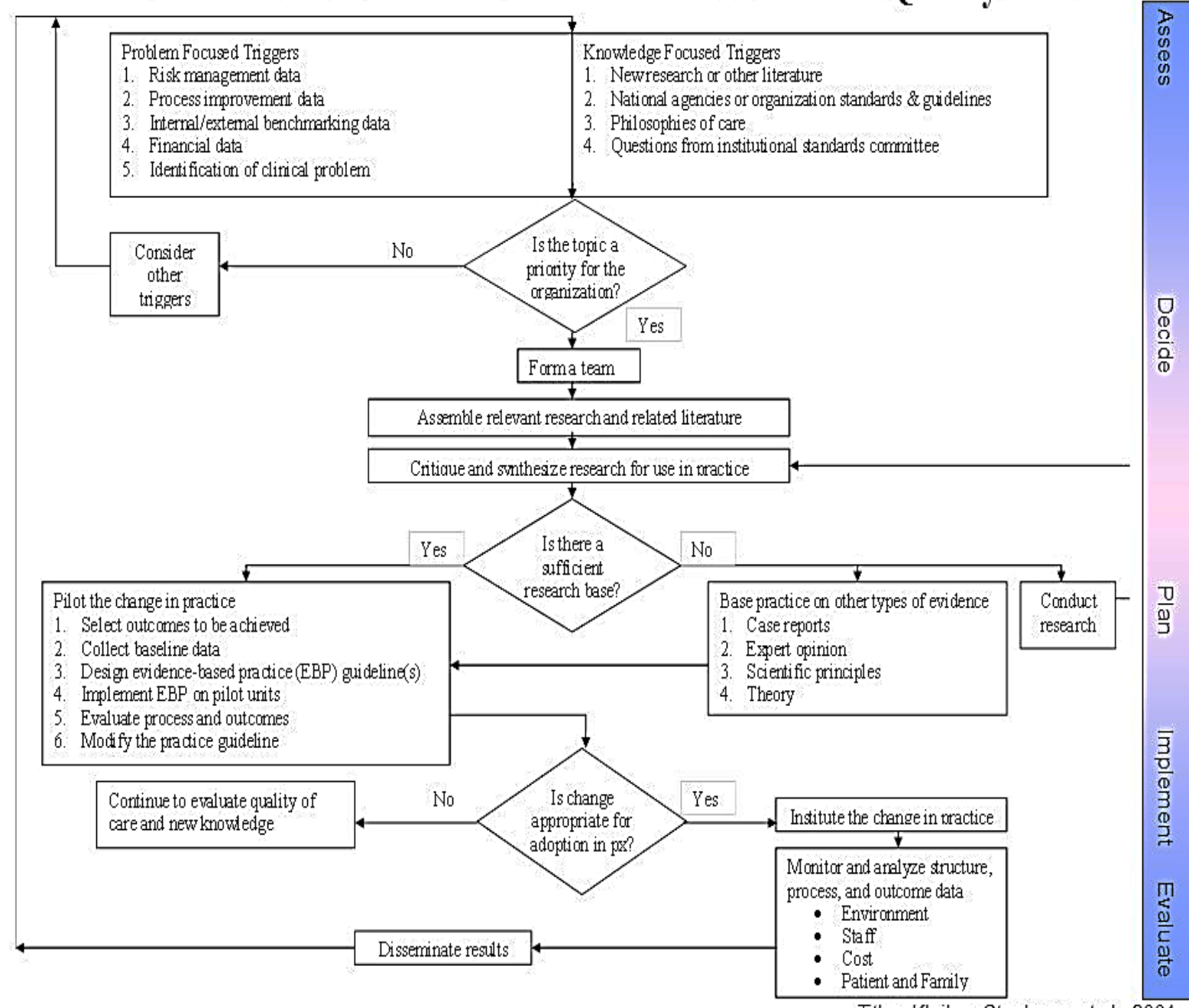

Titler, Kleiber, Steelman, et al., 2001 


\section{Figure 3}

\section{CITI Certification}

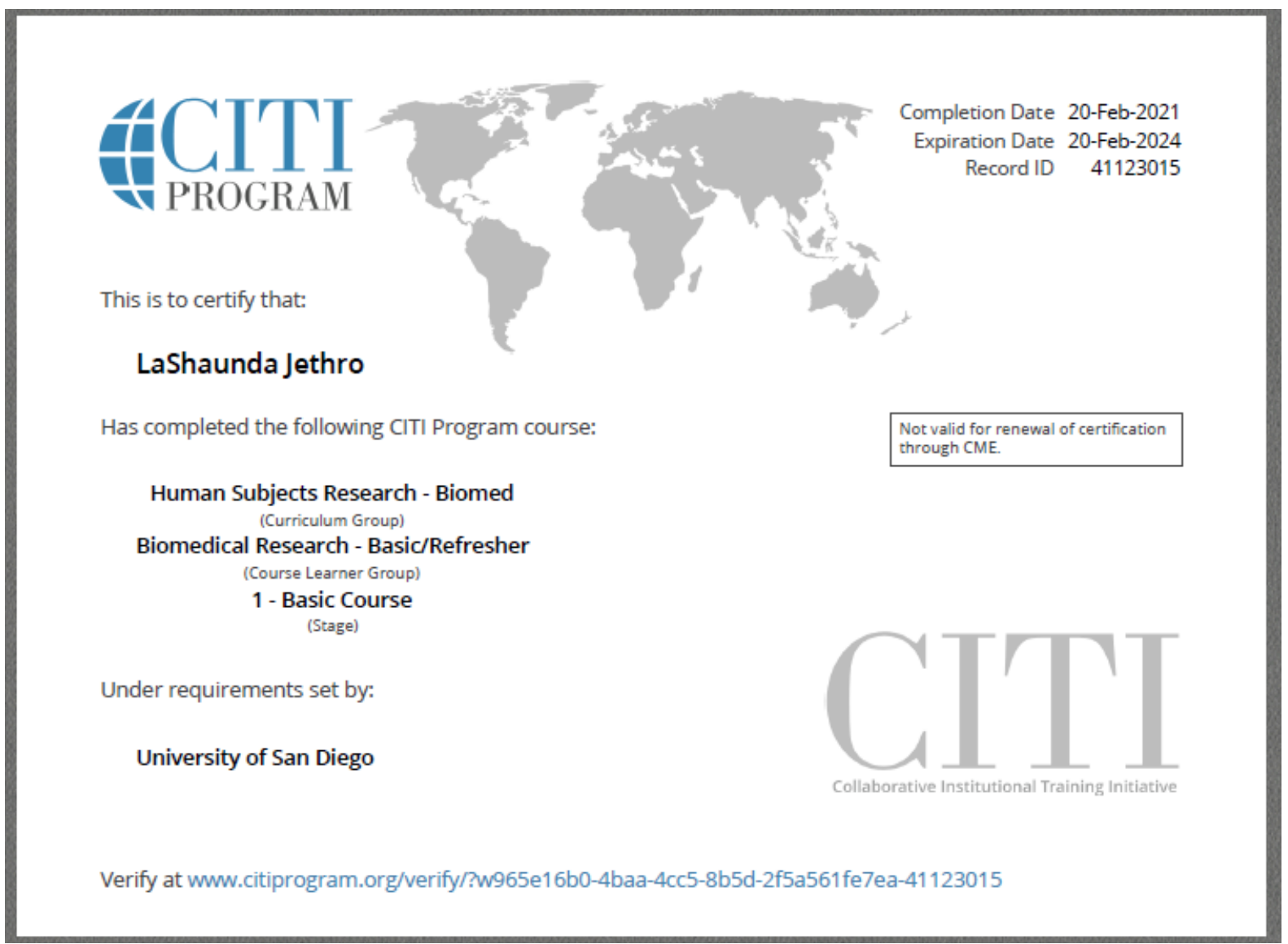




\section{Figure 4}

\section{Exemplars}

\section{AACN DNP Essentials/NONPF Competencies/USD DNP Program Outcomes}

Exemplars

\begin{tabular}{|c|c|c|}
\hline $\begin{array}{l}\text { AACN DNP Essentials \& } \\
\text { NONPF Competencies }\end{array}$ & $\begin{array}{l}\text { USD DNP Program } \\
\text { Objectives }\end{array}$ & $\begin{array}{l}\text { Exemplars } \\
\text { Provide bulleted exemplars that } \\
\text { demonstrates achievement of } \\
\text { each objective }\end{array}$ \\
\hline $\begin{array}{l}\text { DNP Essential I: Scientific } \\
\text { Underpinnings for Practice } \\
\text { NONPF: Scientific Foundation } \\
\text { Competencies } \\
\text { The scientific foundation of nursing } \\
\text { practice has expanded and includes a } \\
\text { focus on both the natural and social } \\
\text { sciences including human biology, } \\
\text { genomics, science of therapeutics, } \\
\text { psychosocial sciences, as well as the } \\
\text { science of complex organizational } \\
\text { structures. In addition, philosophical, } \\
\text { ethical, and historical issues inherent in } \\
\text { the development of science create a } \\
\text { context for the application of the } \\
\text { natural and social sciences. }\end{array}$ & $\begin{array}{l}\text { 2. Synthesize nursing and } \\
\text { other scientific and } \\
\text { ethical theories and } \\
\text { concepts to create a } \\
\text { foundation for advanced } \\
\text { nursing practice. }\end{array}$ & $\begin{array}{l}\text { Fall } 2018 \\
\text { - Completed genogram and } \\
\text { analysis to indicate competency } \\
\text { in the pathogenesis of complex } \\
\text { disease. (DNPC 622) } \\
\text { Fall 2020 } \\
\text { - Narrative reflections of weekly } \\
\text { clinical experiences in an } \\
\text { outpatient psychiatric setting. } \\
\text { Spring 2021 } \\
\text { Proposed use of Iowa Research } \\
\text { Model to support post-graduate } \\
\text { residencies for new NP's. (DNPC } \\
\text { 630) }\end{array}$ \\
\hline $\begin{array}{l}\text { DNP Essential II: Organizational \& } \\
\text { System Leadership for Quality } \\
\text { Improvement \& Systems Thinking } \\
\text { NONPF: Leadership } \\
\text { Competencies/Health Delivery } \\
\text { System Competencies } \\
\text { Advanced nursing practice includes an } \\
\text { organizational and systems leadership } \\
\text { component that emphasizes practice, } \\
\text { ongoing improvement of health } \\
\text { outcomes, and ensuring patient safety. } \\
\text { Nurses should be prepared with } \\
\text { sophisticated expertise in assessing } \\
\text { organizations, identifying system's } \\
\text { issues, and facilitating organization- } \\
\text { wide changes in practice delivery. This } \\
\text { also requires political skills, systems } \\
\text { thinking, and the business and } \\
\text { financial acumen needed for the }\end{array}$ & $\begin{array}{l}\text { 5. Design, implement, and } \\
\text { evaluate ethical health care } \\
\text { delivery systems and } \\
\text { information systems that } \\
\text { meet societal needs and } \\
\text { ensure accountability for } \\
\text { quality outcomes. }\end{array}$ & $\begin{array}{l}\text { Summer } 2018 \\
\text { - Developed organizational } \\
\text { analysis of Heartland Health. } \\
\text { (DNPC 653) } \\
\text { - Performed SWOT analysis to } \\
\text { assess financial stability and } \\
\text { explore areas for business and } \\
\text { resource development including, } \\
\text { evaluation of weaknesses needing } \\
\text { improvement or future } \\
\text { development. (DNPC 653) } \\
\text { Fall 2020 } \\
\text { Gained knowledge regarding } \\
\text { proper use CPT and E\&M codes } \\
\text { to secure proper reimbursement } \\
\text { for services. } \\
\text { Spring 2021 } \\
\text { Researched, and advocated for } \\
\text { post-graduate residency programs } \\
\text { for newly graduated NP's as the } \\
\text { subject for DNP project. (DNPC } \\
\text { 630) }\end{array}$ \\
\hline
\end{tabular}




\begin{tabular}{|c|c|c|}
\hline analysis of practice quality and costs. & & \\
\hline $\begin{array}{l}\text { DNP Essential III: Clinical } \\
\text { Scholarship \& Analytical Methods } \\
\text { for Evidence-Based Practice } \\
\text { NONPF: Quality } \\
\text { Competencies/Practice Inquiry } \\
\text { Competencies } \\
\text { Scholarship and research are the } \\
\text { hallmarks of doctoral education. } \\
\text { Although basic research is viewed as } \\
\text { the first and most essential form of } \\
\text { scholarly activity, an enlarged } \\
\text { perspective of scholarship has emerged } \\
\text { through alternative paradigms that } \\
\text { involve more than discovery of new } \\
\text { knowledge. These paradigms recognize: } \\
\text { (1) the scholarship of } \\
\text { discovery and integration "reflect the } \\
\text { investigative and synthesizing } \\
\text { traditions of academic life"; (2) } \\
\text { scholars give meaning to isolated facts } \\
\text { and make connections across disciplines } \\
\text { through the scholarship of integration; } \\
\text { and (3) the scholar applies knowledge } \\
\text { to solve a problem via the scholarship of } \\
\text { application that involves the translation } \\
\text { of research into practice and } \\
\text { dissemination and integration of new } \\
\text { knowledge. }\end{array}$ & $\begin{array}{l}\text { 4. Incorporate research into } \\
\text { practice through critical } \\
\text { appraisal of existing } \\
\text { evidence, evaluating } \\
\text { practice outcomes, and } \\
\text { developing evidence- } \\
\text { based practice guidelines. }\end{array}$ & $\begin{array}{l}\text { Fall } 2017 \\
\text { Meta-analysis and meta- } \\
\text { synthesis study of Hypertension. } \\
\text { (DNPC 611) } \\
\text { - Synthesized and critiqued } \\
\text { evidence-based research paper } \\
\text { to identify the gap in diagnosis } \\
\text { of Autism for minority children } \\
\text { versus white children. } \\
\text { Spring 2018 } \\
\text { Synthesized and presented } \\
\text { evidence-based research } \\
\text { regarding Complementary and } \\
\text { Alternative Medicine } \\
\text { Modalities. (ANPC 523) } \\
\text { Fall 2019 } \\
\text { Performed three objective } \\
\text { structured clinical examinations } \\
\text { (OSCE) integrating medication } \\
\text { management with motivational } \\
\text { interviewing, solution focus - } \\
\text { based therapy, or trauma } \\
\text { focused cognitive behavioral } \\
\text { therapy to treat patients } \\
\text { diagnosed with substance use } \\
\text { and co-occurring disorders, } \\
\text { PTSD, and depression. }\end{array}$ \\
\hline $\begin{array}{l}\text { DNP Essential IV: Information } \\
\text { Systems/Technology \& Patient Care } \\
\text { Technology for Improvement \& } \\
\text { Transformation of Health Care } \\
\text { NONPF: Technology \& Information } \\
\text { Literacy Competencies } \\
\text { DNP graduates are distinguished by } \\
\text { their abilities to use information } \\
\text { systems/technology to support and } \\
\text { improve patient care and health } \\
\text { care systems and provide leadership } \\
\text { within healthcare systems and/or } \\
\text { academic settings. Knowledge and }\end{array}$ & $\begin{array}{l}\text { 7. Incorporate ethical, } \\
\text { regulatory, and legal } \\
\text { guidelines in the delivery } \\
\text { of health care and the } \\
\text { selection, use, and } \\
\text { evaluation of information } \\
\text { systems and patient care } \\
\text { technology. }\end{array}$ & 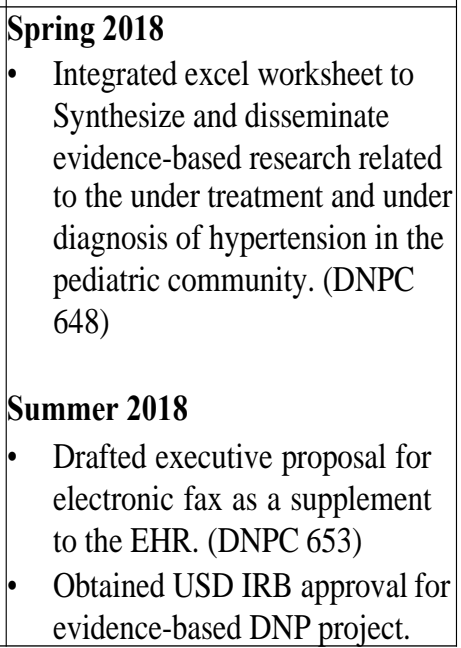 \\
\hline
\end{tabular}




\begin{tabular}{|c|c|c|}
\hline $\begin{array}{l}\text { skills related to information } \\
\text { systems/technology and patient care } \\
\text { technology prepare the DNP } \\
\text { graduates apply new knowledge, } \\
\text { manage individual and aggregate } \\
\text { level information, and assess the } \\
\text { efficacy of patient care technology } \\
\text { appropriate to a specialized area of } \\
\text { practice along with the design, } \\
\text { selection, and use of information } \\
\text { systems/technology to evaluate } \\
\text { programs of care, outcomes of care, } \\
\text { and care systems. Information } \\
\text { systems/technology provide a } \\
\text { mechanism to apply budget and } \\
\text { productivity tools, practice } \\
\text { information systems and decision } \\
\text { supports, and web-based learning } \\
\text { or intervention tools to support and } \\
\text { improve patient care. }\end{array}$ & & $\begin{array}{l}\text { Summer } 2018 \\
\text { - } \quad \text { Submitted executive summary } \\
\text { containing business analysis for } \\
\text { implementation of electronic fax } \\
\text { system (Sfax) to improve } \\
\text { clinical operations. } \\
\text { Summer } 2020 \\
\text { - } \\
\text { Incorporated use of telehealth } \\
\text { (Doxyme) to provide } \\
\text { psychiatric care due to Covid } \\
\text { restrictions preventing in-person } \\
\text { visits. (DNPC 653) } \\
\text { Spring 2021 } \\
\text { Earned certificate of completion } \\
\text { for Human Subjects Biomedical } \\
\text { Research course. (CITI, DNPC } \\
\text { 630) }\end{array}$ \\
\hline $\begin{array}{l}\text { DNP Essential V: Health Care Policy } \\
\text { for Advocacy in Health Care } \\
\text { NONPF: Policy Competencies } \\
\text { Health care policy, whether created } \\
\text { though governmental actions, } \\
\text { institutional decision-making, or } \\
\text { organizational standards, creates a } \\
\text { framework that can facilitate or impede } \\
\text { the delivery of health care services or } \\
\text { the ability of the provider to engage in } \\
\text { practice to address health care needs. } \\
\text { Engagement in the process of policy } \\
\text { development is central to creating a } \\
\text { health care system that meets the needs } \\
\text { of its constituents. } \\
\text { Political activism and a commitment to } \\
\text { policy development are central elements } \\
\text { of DNP practice. }\end{array}$ & $\begin{array}{l}\text { 3. Demonstrate leadership } \\
\text { in collaborative efforts to } \\
\text { develop and implement } \\
\text { policies to improve health } \\
\text { care delivery and outcomes } \\
\text { at all levels of professional } \\
\text { practice (institutional, } \\
\text { local, state, regional, } \\
\text { national, and/or } \\
\text { international). }\end{array}$ & 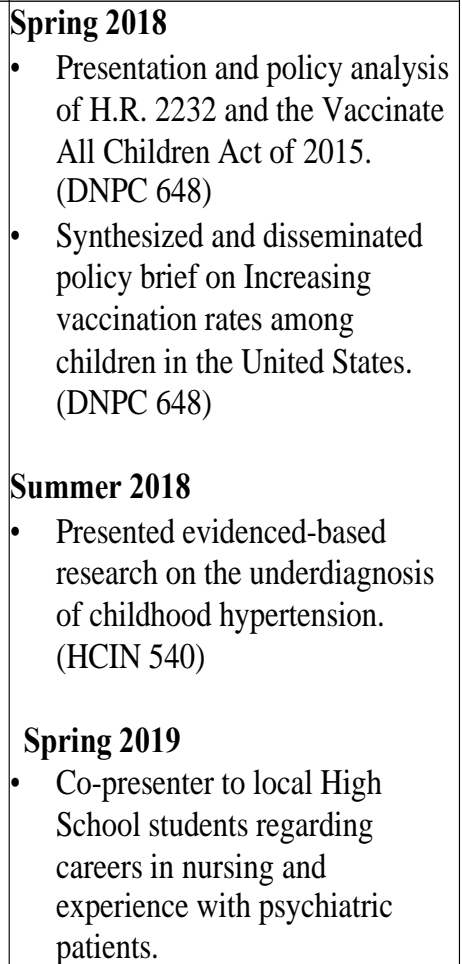 \\
\hline
\end{tabular}




\begin{tabular}{|c|c|c|}
\hline $\begin{array}{l}\text { DNP Essential VI: Interprofessional } \\
\text { Collaboration for Improving Patient } \\
\text { \& Population Health Outcomes } \\
\text { NONPF: Leadership Competencies } \\
\text { Today's complex, multi-tiered health } \\
\text { care environment depends on the } \\
\text { contributions of highly skilled and } \\
\text { knowledgeable individuals from } \\
\text { multiple professions. In order to } \\
\text { accomplish the IOM mandate for safe, } \\
\text { timely, effective, efficient, equitable, and } \\
\text { patient-centered care in this } \\
\text { environment, health care professionals } \\
\text { must function as highly collaborative } \\
\text { teams. DNPs have advanced } \\
\text { preparation in the interprofessional } \\
\text { dimension of health care that enable } \\
\text { them to facilitate collaborative team } \\
\text { functioning and overcome impediments } \\
\text { to interprofessional practice. DNP } \\
\text { graduates have preparation in methods } \\
\text { of effective team leadership and are } \\
\text { prepared to play a central role in } \\
\text { establishing interprofessional teams, } \\
\text { participating in the work of the team, } \\
\text { and assuming leadership of the team } \\
\text { when appropriate. }\end{array}$ & $\begin{array}{l}\text { 1. Demonstrate advanced } \\
\text { levels of clinical practice } \\
\text { within defined ethical, } \\
\text { legal, and regulatory } \\
\text { parameters in designing, } \\
\text { implementing, and } \\
\text { evaluating evidenced- } \\
\text { based, culturally } \\
\text { competent therapeutic } \\
\text { interventions for } \\
\text { individuals or aggregates. } \\
\text { 3. Demonstrate leadership } \\
\text { in collaborative efforts to } \\
\text { develop and implement } \\
\text { policies to improve health } \\
\text { care delivery and outcomes } \\
\text { at all levels of professional } \\
\text { practice (institutional, } \\
\text { local, state, regional, } \\
\text { national, and/or } \\
\text { international). }\end{array}$ & $\begin{array}{l}\text { Spring } 2018 \\
\text { Co-authored and presented } \\
\text { evidence-based research related } \\
\text { to the healthcare complexities } \\
\text { of "Aging in America." (DNPC } \\
\text { 648) } \\
\text { Spring } 2019 \\
\text { - Mentored incoming NP } \\
\text { students. } \\
\text { Summer } 2019 \\
\text { Presented evidence-based } \\
\text { research on the history of } \\
\text { mistrust of medicine in the } \\
\text { African American Community. } \\
\text { Fall 2020 } \\
\text { Obtained certificate of } \\
\text { completion for Screening Brief } \\
\text { Intervention (SBI) in } \\
\text { adolescents focusing on } \\
\text { adolescent substance use, } \\
\text { prevalence, and consequences. } \\
\text { Acquired patient assessment } \\
\text { skills and brief intervention } \\
\text { techniques to promote positive } \\
\text { change in health behaviors. }\end{array}$ \\
\hline $\begin{array}{l}\text { DNP Essential VII: Clinical } \\
\text { Prevention \& Population Health for } \\
\text { Improving Nation's Health } \\
\text { NONPF: Leadership Competencies } \\
\text { Consistent with national calls for action } \\
\text { and with the longstanding focus on } \\
\text { health promotion and disease } \\
\text { prevention in nursing, the DNP } \\
\text { graduate has a foundation in clinical } \\
\text { prevention and population health. This }\end{array}$ & $\begin{array}{l}\text { 6. Employ a population } \\
\text { health focus in the design, } \\
\text { implementation, and } \\
\text { evaluation of health care } \\
\text { delivery systems that } \\
\text { address primary, } \\
\text { secondary, and tertiary } \\
\text { levels of prevention. }\end{array}$ & $\begin{array}{l}\text { Spring } 2018 \\
\text { - Scholarly analysis of H.R. } \\
\text { 2232, The Vaccinate All } \\
\text { Children Act of 2015. (DNPC } \\
\text { 648) } \\
\text { Spring } 2021 \\
\text { - Facilitated workshop (BCLI) to } \\
\text { low-income and underserved } \\
\text { parents focused on "Promoting } \\
\text { Family Time.) (Project } \\
\text { TeamUp) }\end{array}$ \\
\hline
\end{tabular}




\begin{tabular}{|c|c|c|}
\hline $\begin{array}{l}\text { foundation enables DNP graduates to } \\
\text { analyze epidemiological, biostatistical, } \\
\text { occupational, and environmental data } \\
\text { in the development, implementation, } \\
\text { and evaluation of clinical prevention } \\
\text { and population. }\end{array}$ & & $\begin{array}{l}\text { Fall } 2017 \\
\text { - Authored evidence-based } \\
\text { research paper on breast cancer } \\
\text { and BRCA gene testing in } \\
\text { African American women. } \\
\text { (DNPC 625) }\end{array}$ \\
\hline $\begin{array}{l}\text { DNP Essential VIII: Advanced } \\
\text { Nursing Practice } \\
\text { NONPF: Independent } \\
\text { Practice/Ethics Competencies } \\
\text { The increased knowledge and } \\
\text { sophistication of healthcare has resulted } \\
\text { in the growth of specialization in } \\
\text { nursing in order to ensure competence } \\
\text { in these highly complex areas of } \\
\text { practice. The reality of the growth of } \\
\text { specialization in nursing practice is that } \\
\text { no individual can master all advanced } \\
\text { roles and the requisite knowledge for } \\
\text { enacting these roles. DNP programs } \\
\text { provide preparation within distinct } \\
\text { specialties that require expertise, } \\
\text { advanced knowledge, and mastery in one } \\
\text { area of nursing practice. A DNP } \\
\text { graduate is prepared to practice in an } \\
\text { area of specialization within the larger } \\
\text { domain of nursing. }\end{array}$ & $\begin{array}{l}\text { 1. Demonstrate advanced } \\
\text { levels of clinical practice } \\
\text { within defined ethical, } \\
\text { legal, and regulatory } \\
\text { parameters in designing, } \\
\text { implementing, and } \\
\text { evaluating evidence- } \\
\text { based, culturally competent } \\
\text { therapeutic interventions } \\
\text { for individuals or } \\
\text { aggregates. }\end{array}$ & $\begin{array}{l}\text { - Used evidence-based practice to } \\
\text { formulate diagnoses and plan of } \\
\text { care for psychiatric patients } \\
\text { through comprehensive } \\
\text { assessments and patients' } \\
\text { presentation. } \\
\text { - }\end{array}$ \\
\hline
\end{tabular}

KM 5/31/16 - LaShaunda Jethro 


\section{Figure 5}

\section{DNP Poster Presentation}

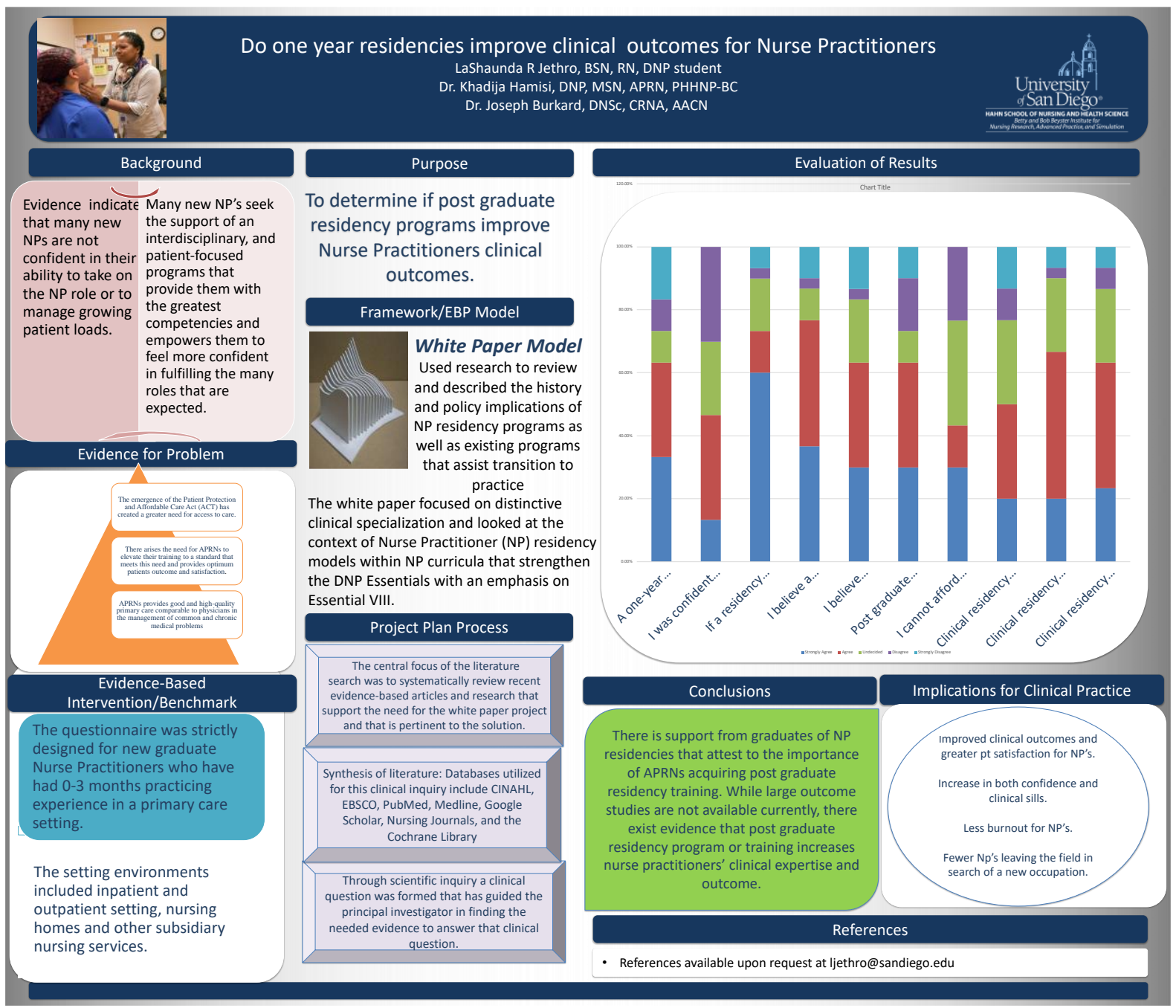

